\title{
Salud porcina: historia, retos y perspectivas
}

José Francisco Rivera-Benítez ${ }^{\mathrm{a} *}$

Jazmín De la Luz-Armendáriz ${ }^{\text {b }}$

Luis Gómez-Núñez ${ }^{\text {a }}$

Fernando Diosdado Vargas ${ }^{a}$

Guadalupe Socci Escatell ${ }^{\text {a }}$

Elizabeth Ramírez-Medina ${ }^{\mathrm{c}, \mathrm{d}}$

Lauro Velázquez-Salinas ${ }^{c, e}$

Humberto Ramírez-Mendoza ${ }^{\text {b }}$

Maria Antonia Coba Ayala ${ }^{\mathrm{f}}$

Catalina Tufiño-Loza ${ }^{\mathrm{a}, \mathrm{b}}$

Marta Macías García ${ }^{\mathrm{g}}$

Víctor Carrera-Aguirre ${ }^{\mathrm{h}}$

Rebeca Martínez-Bautista ${ }^{\mathrm{i}}$

María José Martínez-Mercado ${ }^{\mathrm{i}}$

Gerardo Santos-López ${ }^{\mathrm{j}}$

Irma Herrera-Camacho ${ }^{\mathrm{j}}$

Ignacio Siañez-Estrada ${ }^{\mathrm{k}}$

Manuel Zapata Moreno ${ }^{b}$

${ }^{a}$ Instituto Nacional de Investigaciones Forestales, Agrícolas y Pecuarias. Centro Nacional de Investigación Disciplinaria en Salud Animal e Inocuidad, Km 15. 5 Carretera MéxicoToluca, Palo Alto, Cuajimalpa, CP. 05110, Ciudad de México, México. 
${ }^{\mathrm{b}}$ Universidad Nacional Autónoma de México. Facultad de Medicina Veterinaria y Zootecnia, Ciudad de México, México.

${ }^{c}$ USDA/ARS Plum Island Animal Disease Center. Foreign Animal Disease Research Unit, Greenport NY, USA.

${ }^{\mathrm{d}}$ University of Connecticut. Department of Pathobiology and Veterinary Science, Storrs, CT, USA.

${ }^{\mathrm{e}}$ Kansas State University. College of Veterinary Medicine, Manhattan, KS, USA.

${ }^{\mathrm{f}}$ Práctica privada.

${ }^{\mathrm{g}}$ LAPISA Salud Animal. La Piedad, Michoacán, México.

${ }^{\text {h }}$ SANFER Salud Animal. Ciudad de México, México.

${ }^{\mathrm{i}}$ Zoetis Swine, Ciudad de México, México.

j Instituto Mexicano del Seguro Social. Centro de Investigación Biomédica de Oriente, Atlixco, Puebla, México.

${ }^{\mathrm{k}}$ Benemérita Universidad Autónoma de Puebla. Centro de Química, Instituto de Ciencias, Puebla, México.

* Autor de correspondencia: rivera.francisco@inifap.gob.mx

\section{Resumen:}

En los sistemas de producción porcina, uno de los puntos críticos que deben ser atendidos con estricto rigor, es la salud de los cerdos. La salud, es un componente estructural del bienestar animal y refleja un estado óptimo de los animales, lo que repercute directamente en un mayor desempeño productivo y mejores condiciones de desarrollo. Uno de los eslabones más frágiles de la salud de los cerdos, es la presencia de enfermedades infecciosas más importantes, las cuales pueden representar pérdidas hasta del $100 \%$ de la producción, por lo cual, debe ser un tema de atención constante, y continuamente vigilado por el Médico Veterinario Zootecnista y los productores, en perfecta coordinación con las autoridades sanitarias oficiales. En la actualidad, la implementación de mejores prácticas en la cadena productiva es de interés para productores y consumidores. El control de las enfermedades infecciosas debe ser un tema de colaboración entre los diferentes actores del entorno y ser considerado un bien público, ya que las repercusiones negativas, pueden ser desde el nivel local hasta mundial. En la presente revisión, se abordará la temática relacionada con las 
principales enfermedades infecciosas que ponen en riesgo la salud porcina, el impacto, las principales aportaciones realizadas por el Instituto Nacional de Investigaciones Forestales, Agrícolas y Pecuarias (INIFAP) en sus 35 años de vida, específicamente en el Centro Nacional de Investigación Disciplinaria en Salud Animal e Inocuidad (CENID-SAI), anteriormente conocido como el emblemático CENID-Microbiología o Palo Alto.

Palabras clave: Porcicultura, Enfermedades infecciosas, Tecnología, Innovación.

Recibido: $24 / 11 / 2020$

Aceptado: 11/03/2021

\section{Introducción}

\section{La porcicultura en México y su contexto mundial}

En el mundo se estima que hay cerca de 100 millones de cabezas de cerdo, siendo China, Estados Unidos y Brasil los países con mayor inventario. En 2018, la FAO estimó que el consumo per capita de carne de cerdo a nivel mundial fue de $12.3 \mathrm{~kg}$ al año, por lo que se considera la segunda carne en ser consumida ${ }^{(1)}$. En México, los Estados de Jalisco, Sonora y Puebla son los mayores productores. En 2020, el Servicio de Información Agroalimentaria y Pesquera (SIAP), reportó un estimado de producción de 134,953 t y la FAO registró un consumo per capita de $12.8 \mathrm{~kg}$ en México (2018), por lo cual, la carne de cerdo es considerada como el tercer bien pecuario con mayor participación económica en nuestro país ${ }^{(2)}$. Las unidades de producción porcina en México han sido clasificadas por su nivel de tecnificación y por su objetivo de producción; con respecto al nivel de tecnificación se encuentran las unidades de producción tecnificada, semi-tecnificada y de baja escala, comúnmente conocidas como traspatio ${ }^{(3)}$. Las unidades de producción tecnificadas abarcan del 40 al $50 \%$ del inventario nacional y aporta el $75 \%$ de la producción nacional de carne de cerdo $^{(4)}$. Las unidades de producción semi-tecnificadas tienen un $20 \%$ de participación nacional y son sistemas de producción que van en decremento. Por último, se encuentran las unidades de producción de baja escala o de traspatio, este tipo de producción tiene un $30 \%$ de distribución a nivel nacional ${ }^{(3,4)}$. En estos tres tipos de producción porcina, es importante destacar que, para que la especie pueda ser producida eficientemente, es necesario cumplir con el bienestar animal durante su producción, los parámetros de calidad durante su transporte y sobre todo controlar los principales puntos críticos durante su matanza, con la finalidad de obtener la mejor calidad de carne que será ofrecida al consumidor final. 
La porcicultura mundial se ha visto desafiada constantemente por diversos factores directos o indirectos. En la actualidad, el caso de la pandemia mundial COVID-19, generada por el virus SARS-CoV-2, el cual es responsable de más de 45 millones de casos confirmados, incluyendo más de un millón de fallecimientos, hasta octubre de $2020^{(5)}$. Se ha confirmado que los cerdos no son susceptibles a la infección con SARS-CoV-2, sin embargo, la industria porcina ha sido afectada, ya que se ha restringido la exportación e importación de cerdos, y es común el contagio entre los trabajadores de granjas y en plantas procesadoras, disminuyendo la capacidad de producción de carne de cerdo ${ }^{(6)}$. Se ha registrado un bajo consumo de productos cárnicos durante este periodo; por tal motivo, existieron granjas que debieron eliminar el inventario que estaba destinado a mercado, debido a la falta de ventas. Además, el precio del cerdo en pie fue afectado, en México alcanzando precios sumamente bajos (15 a 16 pesos por kilo), ocasionando que los productores prescindieran de algunos programas de salud empleados en las granjas. La pandemia mundial Covid-19 ha alterado el comportamiento del consumidor, la distribución, la producción y los precios del mercado. Los retrocesos en la producción fueron uno de los mayores desafíos que enfrentó la industria cárnica, pero la capacidad de este sector ha vuelto a la normalidad en gran medida, durante estos últimos meses.

Otro de los factores que afecta la porcicultura son los agentes infecciosos que causan altas tasas de morbilidad y mortalidad. Un ejemplo reciente es, la peste porcina africana (PPA), la cual es una enfermedad viral que causa altas tasas de mortalidad en cerdos domésticos. En el año 2018, se reportaron brotes de esta enfermedad en diferentes provincias de China y actualmente causa brotes en Europa y Asia; la implementación de estrictas medidas de bioseguridad son la herramienta para evitar el ingreso de este agente viral y la despoblación

es el protocolo de control, hasta que se logre el desarrollo de un biológico eficaz ${ }^{(7,8)}$. Afortunadamente, el continente americano aún se mantiene libre de este agente infeccioso y esto lo convierte en uno de los potenciales exportadores de carne de cerdo a China. En este contexto, las exportaciones mexicanas de carne de cerdo a China, reportaron un crecimiento del $929 \%$ durante enero del 2020, al sumar 4,076 t de carne, contra las $396 \mathrm{t}$ reportadas en enero del 2019. Al cierre del 2019, México exportó 30,072 t de cerdo a China, lo que colocó al país asiático como el segundo comprador de este tipo de carne mexicana ${ }^{(9)}$.

\section{La salud porcina, los agentes infecciosos y sus repercusiones}

En la actualidad, la estabilidad de la sociedad humana alrededor del mundo ha sido afectada por varios aspectos, como el crecimiento demográfico, la seguridad alimentaria, la necesidad de métodos de producción más eficaces y sostenibles, y el cambio climático. Se prevé que debido al crecimiento de la población se requerirá un $70 \%$ más de la producción actual de alimentos para el año $2050^{(10)}$. Esto exige sistemas de producción más intensivos, con poblaciones animales más numerosas, lo que propicia el surgimiento de enfermedades 
emergentes y re-emergentes, las cuales son un reto continuo en salud animal. A continuación, se describen las principales enfermedades que deben ser atendidas, algunas son exóticas y otras endémicas; no obstante, todas causan un impacto negativo, en términos económicos y productivos en la porcicultura.

\section{Agentes bacterianos}

\section{Enfermedades respiratorias}

Desde 1960, las enfermedades respiratorias en $\operatorname{cerdos}^{(11)}$ han sido descritas y a partir de entonces, diversas investigaciones se han realizado con el objetivo de identificar a los agentes etiológicos involucrados en ellas. En diferentes estudios realizados en cerdos se ha demostrado que las co-infecciones entre bacterias y virus conducen a una exacerbación en las lesiones pulmonares, esto debido a una mayor reacción inmunológica caracterizada por un aumento en la producción de citocinas proinflamatorias ${ }^{(12)}$. Los agentes relacionados con el complejo respiratorio porcino (CRP) se pueden dividir en patógenos primarios y secundarios o también llamados oportunistas ${ }^{(13)}$. Dentro de los agentes primarios, se encuentran algunas bacterias con algunos serotipos de alta virulencia de Actinobacillus pleuropneumoniae (App), Mycoplasma hyopneumoniae y Bordetella bronchiseptica. En las bacterias incluidas como patógenos secundarios u oportunistas se han reportado a las cepas de baja virulencia de App, Glaesserella parasuis (antes Haemophilus parasuis), Pasteurella multocida y Streptococcus suis ${ }^{(13)}$.

Actinobacillus pleuropneumoniae (App), bacteria Gram-negativa que ocasiona una pleuritis fibrinosa, bronconeumonía hemorrágica y necrótica, que puede provocar un aumento en la mortalidad $^{(14)}$. Las cepas más virulentas de App tienen tropismo por el tracto respiratorio bajo (bronquiolos y neumocitos), su principal daño es por las exotoxinas (Apx I, II, III y IV) que ocasionan lisis celular, provocando las lesiones características ${ }^{(14)}$.

Mycoplasma hyopneumoniae, es causante de la neumonía enzoótica ${ }^{(15)}$. Los mecanismos derivados por M. hyopneumoniae y su participación en el CRP, se pueden clasificar en dos: i) alteración en las células del epitelio ciliado, con pérdida de los cilios y por lo tanto, permisividad a la invasión de patógenos secundarios y ii) alteración de la respuesta inmunológica $^{(15)}$. La infección con $M$. hyopneumoniae inhibe la actividad fagocítica de algunas células de la respuesta inmune innata, como los macrófagos, favoreciendo las infecciones de otros patógenos ${ }^{(15,16)}$. Una infección por M. hyopneumoniae establecida, contribuye a potencializar infecciones virales ${ }^{(12,17)}$. En los últimos años se han llevado a cabo diferentes esfuerzos por eliminar $M$. hyopneumoniae, principalmente en las hembras reproductoras $^{(18)}$. La probabilidad de que la piara se mantenga negativa al menos por un año, después de la eliminación, es del $83 \%{ }^{(19)}$. 
Bordetella bronchiseptica, bacteria Gram-negativa, que puede considerarse como patógeno primario o secundario, dependiendo del momento de infección. En lechones puede ocasionar una bronconeumonia necrótica y hemorrágica, como patógeno primario. Los signos clínicos pueden ir desde un catarro transitorio hasta la rinitis atrófica, cuando se asocia con otro patógeno como Pasteurella multocida. La mayoría de los estudios sobre las interacciones de los patógenos del CRP, se centran en la evaluación de los signos clínicos y el impacto de la enfermedad, sin embargo, los mecanismos involucrados a nivel molecular han sido poco estudiados $^{(12)}$, lo cual abre un campo de investigación en esta área.

Glasserella parasuis, (antes Haemophilus parasuis) bacteria Gram-negativa causante de la enfermedad de Glässer, provoca una poliserositis fibrinosa y septicemia con localización en encéfalo, articulaciones y/o pulmones ${ }^{(13)}$. La mortalidad puede ser elevada, principalmente en poblaciones sin exposición previa ${ }^{(18)}$.

Streptococcus suis, es un coco Gram-positivo encapsulado ${ }^{(20)}$ que afecta principalmente a cerdos de 5 a 10 semanas de edad. Provoca muerte aguda por septicemia, causa meningitis, poliartritis, poliserositis, endocarditis valvular, además puede causar daño en tracto digestivo y genital, ocasionalmente, los cerdos, pueden presentar disnea y cianosis. En cerdos sanos se encuentra de manera habitual en tonsilas y tracto respiratorio superior. Es un microorganismo zoonótico que ha incrementado su importancia en los últimos 10 años, siendo el serotipo 2, el más importante en salud pública ${ }^{(21)}$. S. suis se ha clasificado en 35 serotipos $^{(22)}$ y su distribución depende de la ubicación geográfica ${ }^{(23)}$. En EEUU y Canadá, los serotipos 2 y 3 son los más abundantes, en el caso de México no se tienen datos, pero se puede sugerir que son similares.

En el CENID-SAI se han realizado estudios para identificar la presencia de estos agentes infecciosos; en 1997 se realizó una encuesta serológica en la que se detectó una asociación significativa en la infección bacteriana con $M$. hyopneumoniae, App y la infección con el virus de la enfermedad Aujeszky $(E A)^{(24)}$. En 2008, se evaluó y estandarizó una prueba de PCR en punto final, con la que se identificaron diferentes cepas de App ${ }^{(25)}$. En 2011, se identificó M. hyopneumoniae, por PCR en cerdos infectados de forma temprana, con o sin la presencia de signos clínicos ${ }^{(26)}$.

\section{Enfermedades digestivas}

En las granjas de producción intensiva, las enfermedades entéricas en los cerdos ocasionan pérdidas económicas debido a un incremento en los costos por medicación y al retraso en el crecimiento. 
Brachyspira hyodysenteriae, es considerada como una espiroqueta anaeróbica intestinal, la cual causa una colitis mucohemorrágica conocida como disentería porcina. La disentería porcina afecta a los cerdos en la etapa de crecimiento y finalización, los cuales manifiestan diarrea mucosa moderada sin afectar la condición corporal o, en algunos casos, diarrea hemorrágica con tasas de mortalidad del 50 al $90 \%{ }^{(27)}$. En piaras afectadas, la disentería porcina causa pérdidas económicas debido a la mortalidad, índices de crecimiento disminuidas, una menor conversión alimenticia y a los costos del tratamiento ${ }^{(28)}$.

Lawsonia intracellularis, es una bacteria intracelular obligada, Gram-negativa, causante de la enteropatía proliferativa o ileitis. La enfermedad se caracteriza por un engrosamiento de la mucosa intestinal debido a una proliferación en el epitelio de las criptas intestinales, principalmente localizadas en íleon ${ }^{(29)}$. La enfermedad se manifiesta en forma aguda y crónica. La presentación aguda origina la enteropatía proliferativa hemorrágica, con alta mortalidad y diarrea sanguinolenta, afectando a cerdos en etapa de finalización, y hembras de reemplazo. La adenomatosis intestinal es la manifestación crónica de la enfermedad, de manera subclínica y autolimitante en cerdos jóvenes, aunque es posible la complicación por bacterias oportunistas, resultando en una enteritis necrótica con presencia de exudado fibrinoso y necrosis ${ }^{(30)}$. Tiene una amplia distribución en granjas porcícolas, su impacto económico se debe a que los casos clínicos provocan un menor peso en la finalización y poca conversión alimenticia ${ }^{(31)}$.

Salmonella spp., es una bacteria ubicua. Para el caso de cerdos, S. typhimurium, tiene una presentación entérica con diarrea, consecuencia de una enterocolitis, mientras que $S$. cholerasuis tiene un cuadro septicémico ${ }^{(32)}$. Es más frecuente en animales durante la etapa de destete hasta cinco meses de edad. En la forma superaguda, la septicemia provoca muerte súbita, principalmente en cerdos de dos a tres meses de edad, con hemorragia difusa en diferentes órganos; la forma aguda presenta diarrea amarillenta, fiebre y emaciación, con úlceras, que puede derivar en una forma crónica, con la presencia de úlceras botonosas, necrosis intestinal y estenosis. Los animales infectados permanecen como portadores durante meses y excretan la bacteria intermitentemente, vía heces ${ }^{(33)}$.

Escherichia coli, bacilo Gram-negativo, anaerobio facultativo, clasificado dentro de la familia Enterobacteriaceae, coloniza normalmente la microbiota intestinal de los animales domésticos. Sin embargo, es el agente causal de la diarrea neonatal en lechones y la enfermedad del edema, en la etapa posterior al destete, asociada comúnmente a cepas enterotoxigénicas, las cuales producen como factor de virulencia, enterotoxinas que causan secreción de agua y electrolitos al lumen intestinal, provocando diarrea, deshidratación y acidosis, así como edema ${ }^{(34)}$. Otros factores de virulencia, relacionados con la adherencia e infección de células epiteliales, son la fimbria y el pili, los cuales son identificados para realizar un diagnóstico más preciso del tipo de cepa involucrada en el cuadro clínico. Existen otras cepas que producen la toxina Shiga (Stx2e) causante de la enfermedad del edema ${ }^{(35)}$. 
La colibacilosis tiene implicaciones económicas que resultan de los índices de mortalidad del 50 hasta $90 \%$, las bajas tasas de crecimiento, la pérdida de peso, los costos de tratamiento, por el uso de antibióticos, fármacos antisecretores o probióticos, y la vacunación ${ }^{(36)}$.

En 1998, se estableció por primera vez en México; en el CENID-SAI del INIFAP, la prueba de PCR, con el objetivo de detectar $L$. intracellularis ${ }^{(37)}$. Las ventajas de esta metodología son su versatilidad, rapidez, alta sensibilidad y especificidad. En 2005, se realizó un estudio para determinar la frecuencia de piaras infectadas con L. intracellularis, detectando un $37 \%$ de granjas positivas ${ }^{(38)}$. Con el establecimiento de esta metodología, se brindó servicio de diagnóstico a empresas privadas, y se realizaron diversos estudios sobre los patrones de excreción de L. intracellularis. En 2004, se identificaron fagos causantes de la resistencia microbiana en cepas de Salmonella $\mathrm{spp}^{(39)}$. En estudios recientes, se logró detectar $L$. intracellularis, B. hyodisenteriae y Salmonella spp., en un $26 \%, 11 \%$ y $4 \%$, respectivamente. En el CENID-SAI, se generó y validó la tecnología basada en la detección simultánea de B. hyodysenteriae, L. intracellularis y Salmonella spp., por PCR a partir de una sola muestra de heces. El diagnóstico clínico y de laboratorio para estas tres enfermedades era difícil, laborioso y costoso. Esta tecnología fue transferida a laboratorios privados, los cuales pudieron ofrecer el servicio a los productores para confirmar la presencia de estos agentes en sus piaras. Esto se reflejó en una diferencia en el ingreso neto de los usuarios de la tecnología INIFAP comparado con una tecnología testigo, del $650 \%$, y una derrama económica de $\$ 936,000.00 \mathrm{MN}$, derivados del análisis de 900 muestras de cerdos ${ }^{(40)}$.

\section{Agentes virales}

\section{Enfermedades endémicas}

\section{Infección por Circovirus porcino tipo 2 (PCV2)}

El circovirus porcino (PCV), pertenece al género Circovirus de la familia Circoviridae, son virus con genoma ADN circular monocatenario. Hasta la fecha, se han reportado cuatro tipos de circovirus porcino (PCV1-4) ${ }^{(41,42)}$. Existe una alta diversidad genética de PCV2 y se tienen identificados ocho genotipos (PCV2a-h). Los genotipos de PCV2 no se pueden identificar con serología convencional, ya que tienen alta antigenicidad cruzada, esta característica ha mantenido el uso de las vacunas disponibles contra PCV2. Sin embargo, no existe antigenicidad cruzada entre PCV2 y PCV $3^{(41,42)}$. A la fecha, el PCV1 (contaminante de la línea celular PK-15) es considerado no patógeno en el cerdo ${ }^{(43,44)}$. En el año 1997, el PCV fue asociado a una enfermedad que afectaba a cerdos de destete conocida como síndrome multisistémico de adelgazamiento posdestete (PMWS, en inglés postweaning multisystemic wasting síndrome) $)^{(45,46)}$. El PMWS se encuentra distribuido mundialmente y es habitualmente descrito en cerdos de destete o inicio de la engorda en granjas no vacunadas. 
La seroprevalencia frente a PCV2 dentro de las granjas oscila entre el 15 y $100 \%$, independientemente de la existencia de PMWS ${ }^{(46,47)}$. En el año de 2003, se realizó el primer aislamiento y detección de anticuerpos frente a PCV2 en México. En una investigación retrospectiva se demostró la presencia de anticuerpos contra PCV2 en México, desde el año de 1973. Este estudio mostró que la infección por PCV2 ha sido enzoótica en México durante muchos años antes de la primera descripción del PMWS ${ }^{(48)}$. Estudios epidemiológicos realizados, han detectado hasta un $98 \%$ de seroprevalencia en cerdos de producciones de traspatio $^{(49)}$. Estudios actuales, han demostrado la existencia de los genotipos PCV2a $(12.5 \%)$, PCV2b $(87.5 \%)^{(50)}$, PCV2d y recientemente, PCV3 ${ }^{(51)}$. En 2018, se identificó un $49 \%$ de casos positivos a la presencia de PCV2 y se confirmó la co-infección con el virus de PRRS, estos resultados fueron obtenidos a partir de pruebas moleculares estandarizadas y validadas en CENID-SAI ${ }^{(52)}$.

\section{Infección por Circovirus porcino tipo 3 (PCV3)}

En 2015, en unidades de producción porcina en Estados Unidos, se identificaron problemas reproductivos y síndrome de nefropatía, neumonía y dermatitis porcina; al realizar el diagnóstico molecular para la identificación de PCV2 los resultados fueron negativos, por lo que se decidió realizar estudios de metagenómica, identificando la presencia de un nuevo genogrupo de circovirus porcino, el cual fue nombrado como circovirus porcino tipo 3 $(\mathrm{PCV} 3)^{(53)}$. En años posteriores ha sido identificado en Japón ${ }^{(54)}$, China ${ }^{(55,56)}$, Reino Unido (desde 1992) $^{(57)}$, Italia ${ }^{(58)}$, Alemania ${ }^{(59)}$ y en Suecia ${ }^{(60)}$. Con respecto a América latina, el primer reporte de identificación de anticuerpos específicos en contra de PCV3, fue en muestras obtenidas en unidades de producción porcina de México y EE.UU., estos resultados fueron reportados en $2016^{(53)}$, en 2017 se reportó la presencia del PCV3 en Brasil ${ }^{(61)}$, y se confirmó la presencia de PCV3 en América, Europa y Asia. Los principales signos clínicos asociados a la infección fueron síndrome de desgaste multisistémico post destete, síndrome de nefropatía, dermatitis y falla reproductiva. En México, en 2018, se confirmó la presencia de PCV2a y PCV2 $b^{(50)}$, por lo que se implementaron estrategias de vacunación que han permitido el control de estos signos clínicos, el impacto económico y productivo. Estas estrategias de control habían sido eficientes, sin embargo, a partir de 2013, se reportó la aparición de algunos signos clínicos asociados, y al realizar diagnóstico se descartó la presencia de PCV2, sin embargo, se confirmó la de PCV3. En 2017, en CENID-SAI, INIFAP, se realizó la identificación y amplificación del genoma completo de PCV3, detectado en una unidad de producción con falla reproductiva y en cerdos con signos clínicos asociados al síndrome de desgaste multisistémico posdestete, dermatitis y nefropatía; las secuencias fueron reportadas en el banco mundial de genes (GenBank: MH192340.1 y MH192341.1 $)^{(51)}$. En CENID-SAI se ha continuado con el estudio de esta enfermedad; en 2019 se analizaron muestras de suero obtenidas entre 2012 y 2017, en los estados de Guanajuato y Jalisco se identificó la presencia de PCV3 desde 2012 en ambos estados, con una frecuencia del $31 \%$, además detectó que existe co-infección vPRRS y PCV2. Con las 
muestras positivas se realizaron estudios de secuenciación, caracterización genética y análisis filogenéticos. En 2020, se reportaron las secuencias del genoma completo de PCV3, de muestras de suero de cerdos del estado de Jalisco y Guanajuato; estas secuencias fueron enviadas al GenBank y actualmente se encuentran en revisión. Con estos estudios se confirmó la presencia de PCV3 en México y se establecieron homologías genéticas entre las cepas, sin embargo, es necesario aumentar el número de secuencias representativas de diferentes unidades de producción porcinas, con la finalidad de establecer estrategias de control como el diseño de biológicos para su vacunación.

\section{Síndrome respiratorio y reproductivo porcino (PRRS)}

El síndrome respiratorio y reproductivo porcino (PRRS, por sus siglas en inglés) es una enfermedad causada por un virus que pertenece a la familia Arteriviridae, género Arterivirus. Es un virus envuelto, con genoma ARN de $15 \mathrm{~kb}$ que contiene nueve marcos de lectura abiertos $^{(62)}$. PRRS afecta a cerdos de todas las edades, pero los mayores problemas se producen en las cerdas gestantes y lechones. En las hembras, el cuadro clínico se caracteriza por disminución de la fertilidad, abortos tardíos, aumento en las repeticiones y alta incidencia de nacidos muertos, débiles y momificados. En lechones principalmente ocasiona problemas respiratorios. El PRRS fue descrito por primera vez en 1987 en Carolina del Norte, EE.UU. ${ }^{(63)}$. El virus del PRRS (vPRRS) fue aislado por primera vez en 1991, en Lelystad, Holanda $^{(64)}$. En EE.UU. se logró aislar en 1992 (cepa VR-2332) ${ }^{(65)}$. El vPRRS posee una alta tasa de mutación, generando el surgimiento de diferentes cepas virales las cuales se agrupan en dos genogrupos que son las cepas europeas (EU-PRRS1) y las cepas americanas (NAPRRS2), las cuales presentan una homología del $63 \%$, lo que indica una alta variabilidad genética ${ }^{(66)}$. A pesar del gran impacto productivo y económico, no se ha logrado la obtención de vacunas que sirvan como herramientas de prevención y control para los signos clínicos causados por este agente viral ${ }^{(67)}$. El vPRRS es uno de los problemas infecciosos de origen viral más importantes, por el impacto económico que ocasiona a la industria porcina nacional e internacional. A nivel mundial, se han reportado pérdidas anuales de hasta $\$ 664$ millones de dólares. En 2016, se estimó el gasto económico asociado a este virus en más de 40 granjas en México, identificando pérdidas de más de $\$ 3,000.00$ pesos al año por cerda ${ }^{(68)}$. Las pérdidas económicas en la porcicultura mexicana por esta enfermedad se estiman en 400 millones de pesos al año, por lo que se considera uno de los padecimientos más importantes. En cerdos en la línea de producción el costo estimado es de \$130 a \$260 pesos por animal al año. En México, el primer estudio en el que se mostró serología positiva al vPRRS, fue realizado en cerdos importados de Canadá y Estados Unidos, además se identificó una prevalencia de entre el 2.7 y $13 \%$ en los estados de Sonora, Jalisco, Guanajuato y Aguascalientes ${ }^{(69)}$. En 1997, se reportó que del 78 al $84 \%$ de las unidades de producción porcinas fueron positivas a la presencia de PRRS ${ }^{(70)}$. En el año 2000, se realizó el primer aislamiento viral en México ${ }^{(71)}$. En los últimos años, los estudios epidemiológicos realizados por el CENID-SAI han mostrado que la frecuencia de granjas con animales con anticuerpos 
es elevada, llegando hasta un $70 \%$, en la zona centro del país. En 2007 se generó una prueba de diagnóstico molecular para la detección del vPRRS en CENID-SAI, la cual fue adoptada por el Centro Nacional de Diagnóstico en Salud Animal (CENASA), de la Dirección General de Salud Animal (DGSA). Actualmente en México, se han realizado estudios de caracterización antigénica y genética con las cepas que circulan en México, y se ha reportado que las cepas de PRRS presentan variaciones antigénicas y genéticas en una misma unidad de producción ${ }^{(72)}$. Diferentes grupos de investigadores se encuentran trabajando en el estudio de las regiones antigénicas del vPRRS ${ }^{(73)}$, con el objetivo de identificar cepas prototipos para la elaboración de herramientas de diagnóstico y vacunas, como posibles herramientas que coadyuven en la prevención y control en México.

\section{Enfermedad del ojo azul}

El Rubulavirus porcino (RVP) es el agente causal de la enfermedad del ojo azul de los cerdos, se descubrió a principios de la década de $1980^{(74-76)}$. El RVP está clasificado actualmente como Orthorubulavirus porcino (en inglés, Porcine orthorubulavirus o PRV), dentro de la familia Paramyxoviridae ${ }^{(77)}$. El RVP se ha sido descrito solamente en México ${ }^{(78)}$. La enfermedad se caracteriza por alteraciones neurológicas, respiratorias y reproductivas acompañadas de opacidad de la córnea en cerdos de diferentes edades ${ }^{(75,79-83)}$. El diagnóstico serológico puede realizarse con pruebas de inhibición de hemaglutinación, neutralización viral, inmunoperoxidasa y ELISA. La prueba de inhibición de la hemaglutinación es la más empleada, aunque frecuentemente puede dar falsos positivos, si no es estandarizada correctamente $^{(84)}$. Se ha reportado la detección y cuantificación del RVP mediante RT-PCR en tiempo real ${ }^{(85,86)}$; estas pruebas pueden resultar costosas si son aplicadas en grandes poblaciones. Por lo tanto, existen campos de oportunidad para el desarrollo de pruebas rápidas aplicables en campo. Aun no se ha logrado el control de la enfermedad debido, principalmente, a que los animales pueden presentar cuadros subclínicos e infecciones persistentes $^{(82)}$. La secuenciación de cepas neurovirulentas que afectaron los estados de Jalisco y México en 2015, así como otros estudios, indican que existen variaciones genéticas respecto a los primeros brotes ${ }^{(87)}$. Estos cambios en las proteínas virales pueden generar una diversidad antigénica, lo cual ocasionaría que los anticuerpos producidos contra una variante

pierdan la capacidad de reconocimiento en otras ${ }^{(88)}$. Desde el punto de vista de la salud humana, no se han reportado zoonosis por RVP, aunque si se ha demostrado la presencia de anticuerpos contra el virus en personal veterinario ${ }^{(89)}$. Se ha sugerido que el RVP tiene potencial de ocasionar zoonosis, esto debido al contacto amplio que se presenta entre humanos y cerdos, como ha ocurrido con otros paramixovirus que infectan animales ${ }^{(90)}$. Existen en el mercado dos vacunas comerciales de virus inactivado. Los resultados de estudios realizados, sugieren que el uso de una cepa vacunal no actualizada, puede generar poca protección en contra de las cepas circulantes de $\mathrm{RVP}^{(88)}$, debido a la acumulación de mutaciones. Por ello, se han investigado más opciones, por ejemplo, la posibilidad de emplear proteínas recombinantes de RVP como antígenos para producir una respuesta protectora. Se 
ha estudiado el uso de la proteína HN expresada en E. coli y Pichia pastoris, las cuales inducen la formación de anticuerpos ${ }^{(91,92)}$. Estudios de predicción estructural y antigénica demuestran que, además de la proteína HN, la proteína F, NP y M, potencialmente inducirían una respuesta inmunitaria. Se debe considerar que la proteína $\mathrm{F}$ de los paramixovirus es ampliamente conservada, en la mayoría de los epítopos predichos para RVP se identificaron muy pocas o ninguna variación ${ }^{(93)}$. El RVP ha circulado en México al menos 40 años y el reto es erradicar la enfermedad, por lo que es importante centrarse en tres puntos importantes. Primero, en el desarrollo de un método de diagnóstico efectivo, rápido y económico que permita un uso amplio; segundo, la obtención de una vacuna eficaz contra distintas variantes del virus que circulan normalmente y, tercero, un programa de vigilancia epizootiológica molecular que permita la actualización tanto del diagnóstico como de la vacuna. Estos puntos van a contribuir de forma importante en el control y la erradicación del RVP en granjas porcícolas en México y con ello enfocar esfuerzos hacia otras afecciones importantes en cerdos.

\section{Enfermedad por coronavirus}

Dentro de la familia Coronaviridae existen dos subfamilias: Coronavirinae, con los géneros Alphacoronavirus, Betacoronavirus, Gammacoronavirus y Deltacoronavirus, y la subfamilia Torovirinae ${ }^{(94)}$. Se han identificado cinco coronavirus en cerdos: cuatro pertenecen al género Alphacoronavirus, el virus de la gastroenteritis transmisible (vGET), descrito en 1946; el coronavirus respiratorio porcino (CovRP), originado por mutación del vGET, aislado en 1984 y el virus de diarrea epidémica porcina (vDEP) identificado en 1977 y el coronavirus entérico porcino (SECoV, por sus siglas en inglés) descubierto recientemente, resultado de la recombinación del gen S del vDEP CV777 y el vGET; el virus de la encefalomielitis hemoaglutinante porcina (vEHP), aislado en 1962, que pertenece al género Betacoronavirus; el deltacoronavirus porcino (DCovP), del género Deltacoronavirus, detectado en 2012 ${ }^{(95-97)}$. El vGET fue descrito en 1946, en EE.UU, siendo altamente prevalente durante las décadas de 1970 y 1980. El CovRP tiene su origen debido a una deleción natural en la proteína $\mathrm{S}$ del vGET, modificando su tropismo entérico a uno respiratorio, provocando una enfermedad subclínica en los cerdos. La aparición y diseminación del CovRP trajo como consecuencia una disminución en el impacto de la GET en EE.UU. y Europa, debido a que las granjas seropositivas al CovRP disminuían la mortalidad atribuida a GET, mediante inmunidad cruzada. En contraste con Europa, los brotes con el vGET y el vDEP se observaban de manera frecuente en los países asiáticos, generando coinfecciones y la necesidad de un diagnóstico diferencial ${ }^{(98)}$. La infección con el vGET, el vDEP, el DCovP y el SECov afecta el tracto gastrointestinal de los cerdos ocasionando signos clínicos severos de diarrea y vómito, con tasas de mortalidad elevadas atribuidas a la deshidratación, especialmente en lechones recién nacidos, no existe inmunidad cruzada entre estos coronavirus entéricos ${ }^{(95,98)}$. La presencia de estos patógenos en los

principales países porcícolas se debe a que son altamente contagiosos y al comercio 
internacional de animales vivos o subproductos, extendiéndose en países como China, EE.UU., Canadá, Corea del Sur y México.

La presión inmunológica y el alto pasaje del virus entre los animales, generó mutaciones en el virus, surgiendo cepas variantes altamente patógenas del vDEP, responsables de los brotes epidémicos en 2010. En 2013, el primer brote de DEP en EE.UU. (relacionado filogenéticamente a la cepa AH2012) fue descrito con una mortalidad del 90 a $95 \%$ en lechones, posteriormente se han identificado cepas con menor virulencia que registran inserciones y deleciones (INDEL) en el gen $\mathrm{S}^{(99)}$. De acuerdo a la secuencia de la proteína spike o S, las cepas del vDEP se han clasificado en genogrupos G1a, G1b, G2a y G2b. El grupo G1a incluye la cepa prototipo CV777 y las cepas atenuadas distribuidas históricamente en Europa y Asia; el G1b incluye las cepas S-INDEL, localizadas en Europa, Asia y Norteamérica. Las cepas del genogrupo G2a son exclusivas del continente asiático y en el G2b se encuentra la cepa prototipo de EE UU del año 2013. El DCovP se identificó en 2014, durante los brotes epidémicos de diarrea epidémica porcina (DEP), en coinfección con el vDEP, en EE UU. Mediante un estudio retrospectivo, utilizando muestras colectadas antes de 2014, se comprobó que el DCovP se encontraba circulando previamente a su aislamiento. Los signos son similares a los provocados por el vDEP, sin embargo, la tasa de mortalidad es significativamente menor ${ }^{(96)}$. Los primeros casos de DEP en México ocurrieron en la región del bajío, en Jalisco y Michoacán, en el año 2013. Investigadores del INIFAP y colaboradores fueron pioneros en la atención a productores preocupados por la situación sanitaria. En los primeros casos se observó diarrea, vómito y anorexia en hembras gestantes y cerdos en crecimiento; en lechones se presentó diarrea profusa amarillenta, vómito y mortalidad de $100 \%{ }^{(100)}$. Para el año 2014, la enfermedad se extendió por los estados de Jalisco, Michoacán, Guanajuato, Querétaro, Hidalgo, México, Aguascalientes, Puebla, Veracruz, Nuevo León, Tamaulipas, Sinaloa y Sonora, provocando graves pérdidas económicas. Se comprobó la presencia de la enfermedad debido a las características clínicas y epidemiológicas de los brotes ocurridos en 2013 y principios de $2014^{(101)}$. En ese año, el Servicio Nacional de Sanidad, Inocuidad y Calidad Alimentaria (SENASICA), reconoció de manera oficial la DEP en nuestro país ${ }^{(102)}$.

Las primeras secuencias de las cepas circulantes en México, en el año 2013, fueron reportadas por INIFAP, en el repositorio mundial GenBank. El análisis del impacto económico reveló una disminución del hato porcino de 16.2 millones en el 2013 a 16.1 millones de cabezas al año 2014. Por otra parte, la tasa anual de producción de carne de cerdo reportó un crecimiento de $1.9 \%$ entre 2005 y 2013, sin embargo, en 2014 se registró sólo un $0.5 \%$ de crecimiento. Finalmente, para 2014 se procesaron $8.7 \%$ menos cerdos, que en $2013^{(103)}$. En 2016, se da a conocer el reporte de la enfermedad del año 2014, el cual tuvo índices de mortalidad de $100 \%$ en lechones ${ }^{(104)}$. De acuerdo al último informe enviado a la OIE el 11 de febrero de 2016, los casos de DEP continúan y se considera actualmente una enfermedad endémica en México ${ }^{(102,105)}$. En el laboratorio de Virología del CENID-SAI, se 
realizó la caracterización genética del vDEP circulante en seis estados de la República Mexicana en el periodo 2013-2016, identificando la presencia de los genotipos G2 e INDEL $^{(106)}$. A partir de la identificación del vDEP y el DCovP en diferentes estados ${ }^{(101)}$, en INIFAP se han desarrollado tecnologías para apoyar a los productores, se han generado dos métodos de diagnóstico disponibles: ELISA para la detección de anticuerpos ${ }^{(107)}$ y RT-PCR en tiempo real para la cuantificación del ARN viral. Se han desarrollado investigaciones para aislar, identificación del tropismo, susceptibilidad celular y como parte del proceso de innovación, se ha planteado el desarrollo de un biológico recombinante, el cual ha mostrado resultados satisfactorios en una segunda fase de evaluación ${ }^{(108,109)}$. Actualmente se trabaja en la obtención de mayor masa antigénica a través de procesos de escalamiento ${ }^{(110)}$ para realizar pruebas bajo condiciones de granja y buscar el registro del producto para su transferencia laboratorios interesados del área.

\section{Influenza porcina}

La influenza es una enfermedad respiratoria aguda emergente y reemergente que afecta una gama amplia de aves y mamíferos, incluido el humano. Los virus de influenza A pertenecen a la familia Orthomyxoviridae, presentan una envoltura conformada por las glicoproteínas hemaglutinina (HA) y neuraminidasa (NA), que corresponden a los antígenos de superficie. Estas proteínas participan en la patogenia, determinan los subtipos virales y juegan un rol crucial en la interacción entre el virus, la célula hospedera y el sistema inmune del cerdo. Actualmente se reconocen 18 tipos de HA y 11 tipos de NA ${ }^{(111-115)}$. El mecanismo de transmisión es por vía aérea a través de aerosoles o por contacto directo con secreciones nasales u objetos contaminados (fómites). Cuando el virus ingresa a la mucosa del tracto respiratorio superior, la NA evade la acción defensiva de cilios y mucus, y el inicio de la replicación del virus está mediada por la unión de la HA a los receptores de ácido siálico (SA) de las células epiteliales del tracto respiratorio. Estos receptores se encuentran asociados a la galactosa a través de un enlace $\alpha-2,6-\mathrm{SA}$, presentes en las células epiteliales de la tráquea en humanos y $\alpha-2,3-\mathrm{SA}$, presentes en las células epiteliales del tracto intestinal de las aves, principalmente. Sin embargo, se ha demostrado su presencia en células del tracto respiratorio en humanos ${ }^{(116)}$.

El cerdo expresa receptores para virus humanos y aviares, dando lugar a la posibilidad de generar nuevos subtipos virales ${ }^{(117,118)}$. Los subtipos H1N1, H3N2 y H1N2 de virus de influenza porcina son los más frecuentemente reportados ${ }^{(114,119,120)}$. Los brotes de enfermedad se observan generalmente en la época invernal con una morbilidad casi del $100 \%$ y mortalidad cercana a $1 \%{ }^{(121,122)}$. Debido a que esta enfermedad es una zoonosis y por lo tanto de importancia en la salud pública, debe considerarse el diagnóstico temprano y oportuno del virus de influenza porcina ${ }^{(123)}$. El diagnóstico debe realizarse mediante pruebas de laboratorio que incluyen, aislamiento viral, RT-PCR y pruebas serológicas. Además, se debe efectuar el diagnóstico diferencial ${ }^{(122)}$. Durante el 2009, se presentó la primera pandemia de influenza 
del siglo, ocasionada por el subtipo $\mathrm{pH} 1 \mathrm{~N} 1^{(124)}$. Se demostró que los cerdos son susceptibles a este subtipo ${ }^{(125)}$; en estudios retrospectivos se ha registrado seropositividad desde el año $2009^{(126)}$. El origen y las características genéticas y antigénicas de estos virus difieren según el continente o región en el que se aíslen, debido a dos fenómenos, la recombinación y la deriva genética ${ }^{(115,127)}$. En la actualidad, la enfermedad se encuentra ampliamente distribuida en todos los países productores de porcino, cursando de forma endémica en México ${ }^{(120)}$. En 2004, se realizó un estudio en el que se determinó la asociación del PRRS con otros agentes virales y bacterianos en los que se incluyó influenza porcina ${ }^{(128)}$. En 2016, en un estudio experimental, identificaron que la co-infección del virus de influenza A H1N1, en conjunto con el Rubulavirus porcino, exacerba la enfermedad respiratoria en cerdos en crecimiento $^{(129)}$. En CENID-SAI se trabaja actualmente en la validación de pruebas de diagnóstico molecular, serológico y en el desarrollo de un biológico universal que confiera inmunidad, indistintamente del subtipo que circule en la granja.

\section{Parvovirosis}

El parvovirus porcino (PPV, recientemente llamado Ungulate Protoparvovirus 1) causa trastornos reproductivos en cerdas ${ }^{(130)}$. Debido a la ausencia de la respuesta inmunológica en el embrión o el feto en etapas tempranas, el virus puede replicarse, por lo que, ocurre la muerte de los productos ${ }^{(131)}$. El PPV se encuentra presente en las áreas con mayor producción porcina, describiéndose ampliamente en Estados Unidos de Norte América, China, Alemania, Europa, Hungría, México, Colombia y Cuba. Una gran proporción de hembras primerizas se infectan naturalmente con PPV antes de ingresar al hato reproductor ${ }^{(131,132)}$. A pesar del uso continuo de vacunas, recientemente se han descrito nuevas cepas. Se consideraba que el PPV tiene un genoma más conservado que otros parvovirus y virus ssDNA, el primer análisis evolutivo se realizó en 2011, estudiando los virus que afectan a cerdos en producción intensiva ${ }^{(133)}$ y a jabalíes ${ }^{(134)}$, se encontraron altas tasas de mutación (aproximadamente $3^{-5} \times 10^{-4}$ ) en el gen VP. Las principales divergencias se introdujeron en los últimos 10 a 30 años. Esta historia evolutiva, es similar a la de los parvovirus carnívoros y humanos, lo que sugiere que las altas tasas de mutación pueden ser típicas de los parvovirus porcinos. Los estudios con cepas de eventos clínicos en varios países, incluidos Austria, China, Rumania y Suiza, han informado la existencia de seis genotipos, con nuevos perfiles y grupos (A, B y E), con predominio de cepas de cerdos domésticos observadas en los Clusters C y D en Europa y en Cluster F en China ${ }^{(133-136)}$.

Se han descrito perfiles moleculares de nuevas cápsides con distintas propiedades antigénicas, incluidos los virus utilizados en vacunas comerciales ${ }^{(137)}$. Estos hallazgos, han llevado a la hipótesis de que la aparición de nuevos perfiles de cápside podría deberse a la adaptación viral a las vacunas más utilizadas y, por lo tanto, puede representar "mutantes de escape" en una población parcialmente inmune ${ }^{(133,134)}$. El hecho de que los nuevos parvovirus porcinos se hayan encontrado en cerdos domésticos y jabalíes sugiere un flujo genético 
interespecie activo ${ }^{(132)}$. Como el PPV es capaz de replicarse en células de origen bovino y humano, su rango de hospedadores puede ser más amplio de lo que se piensa comúnmente. En 1991, se identificaron de anticuerpos específicos en contra de parvovirus porcino en cerdas y ratas ${ }^{(138)}$. En 1996, investigadores del CENID-SAI, identificaron que no existe diferencia estadística entre la inmunidad otorgada por la vacunación, con la inmunidad que confiere la infección natural y que el uso de la vacunación no previene completamente los problemas reproductivos asociados a la infección por este virus ${ }^{(139)}$. En 2004, también condujeron un estudio que se basó en identificar la asociación que existe entre el virus de PRRS con otros agentes infecciosos y describieron que, con parvovirus, no se encontró ninguna asociación estadística, ya que todas las cerdas presentaron anticuerpos en contra de este virus ${ }^{(128)}$. En la CDMX se ha descrito la seroprevalencia en cerdos de traspatio durante el año 2000-2009 ${ }^{(140)}$. Es necesario continuar con el monitoreo de PPV en las diferentes regiones productoras de cerdos del país, para determinar la epidemiología y tener una imagen de la distribución a nivel nacional. Con acciones como el establecimiento de métodos de diagnóstico eficientes y actualización de cepas vacunales para PPV, se ayudará a fortalecer las estrategias para el control de la enfermedad.

\section{Enfermedades exóticas}

\section{Fiebre porcina clásica}

Uno de los problemas sanitarios más grandes en la porcicultura mexicana en las décadas pasadas, fue la fiebre porcina clásica. En 2018, se reconoció internacionalmente, la erradicación de esta enfermedad y se ha mantenido el estatus de libre en todo el territorio nacional. La fiebre porcina clásica es causada por un Pestivirus de la familia Flaviviridae. Es una enfermedad altamente contagiosa, que ocasiona, como principales signos, fiebre, inapetencia, debilidad general, deterioro neurológico y hemorragias. La morbilidad y mortalidad en casos agudos puede alcanzar el $100 \%{ }^{(141)}$. En 1975, los esfuerzos realizados por el INIP (ahora INIFAP), a través del trabajo realizado por el Dr. Pablo Correa, en coordinación con los científicos de la Universidad de Cornell, U.S.A., dieron como resultado que se obtuviera con una excelente vacuna, la PAV-250 (porcine attenuated virus-passage 250), que demostró tener características superiores a las vacunas comerciales existentes. Mediante estudios se identificó que la vacuna era inocua, que poseía una potencia satisfactoria y que no se diseminaba. La tecnología desarrollada se puso al servicio de la Productora Nacional de Biológicos Veterinarios (PRONABIVE), y a la industria privada (Laboratorios SANFER y Litton), hecho que contribuyó al éxito de la Campaña Nacional de Erradicación de la FPC. Se realizaron estudios con la vacuna PAV-250 para analizar la estabilidad del biológico ${ }^{(142)}$ y la potencia ante el desafío con cepas altamente virulentas ${ }^{(143)}$. De la misma forma, se comprobó la seguridad al aplicar la vacuna en diferentes etapas productivas $^{(144,145)}$. Con la validación de la PAV-250 en condiciones de campo, se concluyó 
que al ser aplicada en zonas con brotes frecuentes de la enfermedad era efectiva y segura. Todos los trabajos desarrollados en INIFAP sobre la vacuna PAV-250, contribuyeron de forma importante a la erradicación de la enfermedad ${ }^{(146)}$. Como parte del proceso, fue de vital importancia contar con métodos y técnicas para el diagnóstico de la enfermedad. Para la detección del virus, se elaboraron diferentes lotes de conjugado que resultó altamente específico, de excelente calidad y con un título satisfactorio. Este fue constatado por el CENASA ya que lo utilizó de manera rutinaria. También fue comercializado a la industria privada y proporcionado a través de la FAO (ONU), a varios países de Latinoamérica. Por otra parte, en el año 2003, se estableció por primera vez la técnica de RT-PCR para la detección del virus de la FPC. La prueba se comparó con las pruebas oficiales de diagnóstico establecidas por la campaña de control y erradicación de la enfermedad, inmunofluorescencia directa y aislamiento viral. Resultó comparable con ambas técnicas, por lo que se recomendó utilizarla como una prueba confirmatoria de la enfermedad ${ }^{(147)}$. Con la tecnología establecida se logró determinar la cinética del virus vacunal y la caracterización de cepas de campo ${ }^{(148)}$. Con el empleo generalizado de la vacuna PAV-250 se logró erradicar la FPC en el país en el año 2009. Se estima que el empleo de esta vacuna, evitó pérdidas de al menos 26 mil millones de pesos en las etapas más críticas de la campaña de control y erradicación de esta enfermedad.

\section{Enfermedad de Aujeszky}

La enfermedad de Aujeszky (EA) fue la segunda enfermedad de los cerdos que requirió la implementación de una campaña nacional para su control y erradicación. En la actualidad, se considera erradicada en México. El agente etiológico es el alfaherpesvirus porcino 1, el cual causa, principalmente, una severa enfermedad neurológica en cerdos jóvenes, en animales adultos las manifestaciones incluyen cuadros respiratorios y falla reproductiva ${ }^{(149)}$. En los países dónde la enfermedad de Aujeszky (EA) se encuentra de manera endémica, provoca pérdidas económicas elevadas y constituye una barrera para el comercio de los cerdos y subproductos. La EA todavía afecta a algunos países de Europa, Asía y Sudamérica. En México, la EA fue diagnosticada por primera vez en bovinos en el año de $1945^{(150)}$, posteriormente se logró realizar su aislamiento y tipificación ${ }^{(151)}$. Los brotes en cerdos fueron observados a finales de la década de los setentas. A principios de la década de los $90 \mathrm{se}$ realizaron estudios epidemiológicos enfocados en la evaluación sanitaria en animales de granjas porcinas y cerdos de traspatio ${ }^{(152-154)}$. Estos estudios sirvieron para que las autoridades de salud animal tomaran decisiones en la campaña en beneficio de la porcicultura nacional. Con la generación de conocimientos basados en estudios epidemiológicos, evaluación de vacunas, el empleo de una vacuna deletada y de la prueba de ELISA para la detección de animales infectados con el virus de campo, el 24 de junio de 2015, el país fue declarado libre de la EA. La vacuna empleada en la Campaña Nacional contra la Enfermedad de Aujeszky (NOM-007-ZOO-1994) y que fue clave en este enorme esfuerzo, fue elaborada a partir de una cepa con una deleción en el gen gE. Previamente, diversas cepas vacunales empleadas 
en México fueron evaluadas para identificar cuales conferían mayor protección ${ }^{(155)}$. En el año 1997, en el INIFAP se desarrolló y evaluó una metodología de Dot-ELISA propuesta como prueba tamiz alternativa para la detección de anticuerpos contra el virus de la EA. En el estudio se reportó una alta concordancia con la prueba de seroneutralización ${ }^{(156)}$. A petición de las autoridades del CENASA, en el año 2012 se estableció la prueba de reacción en cadena de la polimerasa (PCR) para la detección del virus de EA. La prueba mostró una alta sensibilidad y especificidad y fue recomendada como una prueba complementaria a las establecidas en la campaña de control y erradicación de la enfermedad ${ }^{(157)}$. Posteriormente, se generó la prueba de diagnóstico molecular simultáneo de la EA y la neumonía enzoótica en cerdos. Ésta fue adoptada por el Laboratorio de Investigación y Patología S.A. de C.V., ubicado en el municipio de Tepatitlán, Jalisco. La tecnología adoptada, permitió a los productores detectar al agente infeccioso de manera temprana, y así reducir sus gastos por medicación hasta en un $15 \%$ en las etapas de desarrollo y finalización, y un $10 \%$ por retraso en el crecimiento. Por otra parte, esta tecnología contribuyó a la campaña de control y erradicación de la Enfermedad de Aujeszky al ser empleada como una prueba de diagnóstico complementaria en la vigilancia epidemiológica de la región.

\section{Peste porcina africana}

El virus de la peste porcina africana (vPPA) es un arbovirus responsable de producir la enfermedad que lleva el mismo nombre (PPA) y representa en la actualidad una de las principales amenazas económicas para la porcicultura en el mundo, debido a su elevada tasa de morbilidad y mortalidad en cerdos domésticos y salvajes ${ }^{(158)}$. El vPPA es un virus de doble cadena de ADN y único miembro de la familia Asfarviridae ${ }^{(159)}$. La secuencia del gen B646L, ha sido utilizado para caracterizar al vPPA en 22 genotipos (I-XXII), sin embargo, no es predictiva de la virulencia ${ }^{(160)}$. En términos de virulencia, las diferentes cepas del vPPA pueden mostrar características clínicas contrastantes que van desde presentaciones agudas, asociadas con cuadros de fiebre hemorrágica y muerte en pocos días posteriores a la infección, a presentaciones crónicas con una presentación subclínica, siendo los mecanismos biológicos relacionados con las diferencias de virulencia entre cepas, desconocidos en la actualidad $^{(161)}$. El vPPA fue descrito por primera vez en Kenia en el año de 1921, desde entonces se ha mantenido endémico en un ciclo selvático entre garrapatas y jabalíes, siendo estos últimos capaces de producir viremia durante la infección, sin desarrollar signos clínicos $^{(158)}$. Los primeros reportes de vPPA (genotipo I) fuera del continente africano fueron descritos entre las décadas de los cincuentas y los ochentas en Rusia, España, Italia, Francia, Sardina, Malta, Bélgica, Holanda, Brasil, Cuba y las islas del Caribe ${ }^{(158)}$. Los últimos brotes en el continente americano se registraron en 1984, mientras que el vPPA fue erradicado a mediados de la década de los noventas en países fuera del continente africano, con excepción de Portugal donde se registró un brote aislado en 1999, y la isla de Sardina, donde el virus se ha establecido de manera endémica hasta la actualidad ${ }^{(162,163)}$. En el año 2007, se registró la emergencia del vPPA relacionado al genotipo II, el cual emergió en la República de Georgia 
y se diseminó en diversos países en Europa y Asia ${ }^{(164)}$. De acuerdo con la OIE, uno de los más recientes reportes fue en cerdos salvajes de Alemania, el 10 de septiembre del 2020, entre los años de 2016 y 2020 en Europa se han reportado el $67 \%$ de los brotes asociados con este genotipo, principalmente en cerdos salvajes. Por otro lado, en términos de mortalidad, Asia representa el $82 \%$, con un total de 6,733,791 cerdos domésticos muertos. La elevada virulencia de cepas asociadas con el genotipo II ha sido evidenciada experimentalmente en cerdos domésticos y jabalíes, se ha identificado hasta el $100 \%$ de mortalidad de los animales infectados en un lapso no mayor a los 7 a 10 días posteriores a la infección $^{(165-168)}$.

Indudablemente, uno de los retos más importantes en términos de control y prevención de la PPA, es el desarrollo de una vacuna eficaz, la cual no existe de manera comercial en la actualidad. Diferentes estrategias han sido empleadas con la finalidad de obtener una vacuna contra el vPPA ${ }^{(169)}$, siendo las vacunas atenuadas los candidatos más prometedores ${ }^{(170)}$. En este sentido, la obtención de candidatos vacunales atenuados se ha basado en la deleción selectiva de genes del vPPA ${ }^{(166,167,171-174)}$. Uno de los candidatos vacunales más prometedores en la actualidad es el virus recombinante ASFV-G/ $\Delta \mathrm{I} 77 \mathrm{~L}^{(167)}$. Esta recombinante fue desarrollada mediante la deleción del gen I177L de la cepa altamente virulenta Georgia (genotipo II) del vPPA. En las pruebas iniciales, ninguno de los cerdos inoculados con diferentes dosis $\left(1 \times 10^{2}-1 \times 10^{6} \mathrm{HAD}\right)$ de la recombinante ASFV-G/AI77L, desarrollaron signos clínicos. De manera interesante, después de 28 días de la inoculación, el $100 \%$ de los animales logró sobrevivir al desafío con la cepa parental, produciendo en estos animales una inmunidad de tipo estéril. Los resultados son prometedores; sin embargo, aún es necesario mayor investigación. Otro cuestionamiento interesante, planteado previamente por otros autores ${ }^{(170)}$, es asociado con la capacidad de los vPPA atenuados de establecerse de manera endémica en las regiones donde se usen este tipo de vacunas, debido a que la presencia de una fase de viremia producida por virus como ASFV-G/AI77L, lo que podría representar una fuente de virus para las garrapatas, con el potencial de producir ciclos selváticos.

Todos estos cuestionamientos reflejan la complejidad en el control de la PPA y la necesidad de realizar múltiples trabajos de investigación en el corto, mediano y largo plazo. Si bien la PPA es una enfermedad que no se encuentra en el territorio mexicano, es fundamental contar con un sistema de diagnóstico y prevención contra la misma. El Servicio Nacional de Seguridad, Inocuidad y Calidad Agroalimentaria (SENASICA), además de contar con un laboratorio de alta seguridad nivel 3, además cuenta con una red laboratorios a lo largo de México, todos ellos dirigidos por la Comisión México-Estados Unidos para la Prevención de la Fiebre aftosa y otras enfermedades (CPA). Con base en esta infraestructura, se considera que uno de los mayores retos para México, es mantenerse a la vanguardia en términos de diagnóstico y capacitación de los involucrados en laboratorio y en campo. En este sentido es posible sugerir la realización de convenios de colaboración interinstitucional con laboratorios importantes en la región, como el de Plum Island Animal Disease Center, en los Estados 
Unidos y el National Center for Foreign Animal Disease, en Canadá, los cuales están dedicados a realizar diagnostico e investigación de múltiples enfermedades virales con impacto económico para los animales domésticos. Asimismo, se puede proponer la creación de un grupo de armonización de diagnóstico de PPA entre los tres países. Finalmente, es importante que la Productora Nacional de Biológicos Veterinarios (PRONABIVE) tenga una participación proactiva en cuanto a la posibilidad de obtener licencias para el uso de diferentes candidatos vacunales del vPPA, y estar así preparada para brindar una respuesta rápida en caso de la llegada de esta enfermedad a México.

\section{Retos y perspectivas}

La creciente presión de producción porcina, la amplia red de importaciones-exportaciones, la constante evolución de los agentes patógenos que les permite desarrollar nuevos mecanismos de adaptación y diversificación, y el cambio climático, son algunos de los retos que enfrenta la industria porcícola mundial. Los protocolos de control basados en la despoblación y repoblación del hato, históricamente han sido prácticas empleadas para frenar el daño ocasionado por enfermedades de alto impacto. En la actualidad, los grandes avances tecnológicos en el desarrollo de biológicos eficaces, herramientas de diagnóstico, desarrollo e implantación de medidas de bioseguridad entre otros, han contribuido positivamente en la resolución de dichos retos, disminuyendo la transmisión de enfermedades y evitando, en algunos casos, el uso de métodos de control tan agresivos. Es importante que en nuestro país se realicen estudios más completos sobre las cepas y serotipos predominantes, así como una mejora en las técnicas de diagnóstico para poder evaluar mediante métodos moleculares, con un perfil genético, que permita conocer las propiedades y virulencia de los agentes infecciosos. Los modelos de infección requieren optimización y tienen el potencial de mejorar el conocimiento sobre la patogenicidad de la enfermedad; estos modelos contribuirán significativamente para el desarrollo de nuevas vacunas. En los siguientes años, en los que las restricciones de antibióticos y el consumo de carne de cerdo se incrementarán; el uso de vacunas efectivas será un factor importante. Actualmente, las vacunas autógenas han mostrado alta efectividad, en Europa y Estados Unidos la utilización de las mismas se está regulando con buenas prácticas de fabricación (BPF), aunque hace falta la validación con estudios de eficacia.

El país necesita disminuir y en su caso, evitar la dependencia tecnológica que se tiene del extranjero, para ello, el INIFAP continuará con investigaciones enfocadas en la generación de pruebas de diagnóstico y vacunas basadas en la biotecnología y biología molecular. La adopción de estas tecnologías, contribuirá a complementar un conjunto de herramientas, encaminadas a preservar la salud de los animales y como consecuencia, mejorar la productividad de las unidades de producción porcina. Con este antecedente, se puede implementar un programa de apoyo a pequeños y medianos productores, dirigido a fortalecer 
la sanidad en las piaras y con esto mejorar su productividad a corto y mediano plazo. Un punto importante a considerar durante los siguientes años, es el aumento de consumo de carne de cerdo, no sólo a nivel nacional, sino a nivel internacional, para esto hay que considerar la sanidad en las granjas porcinas, ya que el manejo adecuado y control de los diferentes patógenos permitirá una mayor producción y la reducción en los costos de la misma.

\section{Conclusiones}

Se debe trabajar en estrategias de control y erradicación, bajo la premisa de que muchas de las enfermedades son controlables a través de las buenas prácticas pecuarias. El diagnóstico oportuno y eficaz debe proponerse como método de control y prevención en las unidades de producción, así como la vacunación, incentivando la actualización y empleo de cepas propias, que circulan a nivel nacional. Se deben reforzar las medidas de bioseguridad y favorecer la tecnificación de unidades productivas, mediante la divulgación de la información y transferencia de tecnología a pequeños y medianos productores. Fomentar la aplicación de pruebas de diagnóstico en unidades de producción para identificar la circulación de los agentes infecciosos, para establecer la prevalencia en diferentes regiones del país y definir programas de control. Desarrollar métodos de diagnóstico validados, de fácil aplicación, con sensibilidad y especificidad adecuadas, empleando muestras colectadas con procedimientos no invasivos. Se deben diseñar estudios que evidencien la eficacia de las vacunas disponibles comercialmente, en la población objetivo (cerdas gestantes o sus camadas). En el proceso de innovación, se debe impulsar el desarrollo de biológicos nacionales utilizando diferentes estrategias y formulaciones (virus inactivado, atenuado, vacunas subunitarias, de partículas replicantes, vacunas de ADN, vectorizadas, etc.), con la evaluación de seguridad, eficacia y mejor relación costo-beneficio. Todas estas tecnologías desarrolladas por el INIFAP, podrán beneficiar a los productores, logrando con ello mejores rendimientos y ganancias.

\section{Agradecimientos}

A todos los investigadores del CENID-Microbiología Animal que entregaron su vida profesional a la investigación en enfermedades del cerdo, en especial al M.A. Pablo Correa Girón $^{\dagger}$, M en C. Atalo Martínez Lara ${ }^{\dagger}, M$ en C. María Antonia Coba Ayala, M en C. Laura Zapata Salinas, Dr. Antonio Morilla González y todo el personal técnico y de apoyo que laboró y labora actualmente en el INIFAP. Al proyecto FONSEC SADER-CONACYT 201706-292826.

\section{Conflictos de interés}

Los autores declaran no tener ningún conflicto de interés con la información presentada. 


\section{Literatura citada:}

1. FAO. Food and agriculture organization. FAOSTAT. Statistical databases. Food and Agriculture Organization of the United Nations. 2020. http://www.fao.org/statistics/es/. Consultado 10 Oct, 2020.

2. SIAP. Servicio de información agroalimentaria y pesquera. Secretaría de Agricultura, Ganadería, Desarrollo Rural, Pesca y Alimentación. 2010. http://www.siap.gob.mx. Consultado 10 Oct, 2020.

3. Montero LE, Martínez GR, Herradora ML, Ramírez HG, Espinosa HS, Sánchez HM, et $a l$. Alternativas para la producción porcina a pequeña escala. 1era ed. Ciudad de México, México: Universidad Autónoma de México, Facultad de Medicina Veterinaria y Zootecnia; 2015.

4. Trujillo OM. Ed. Introducción a la Zootecnia. 1era ed. Ciudad de México, México: Universidad Autónoma de México, Facultad de Medicina Veterinaria y Zootecnia; 2006.

5. WHO. World Health Organization. Coronavirus Disease (COVID-19) Dashboard. (2020). https://covid19.who.int/. Accessed 10 Oct, 2020.

6. Segalés J. Are pigs susceptible to SARS-CoV-2?. 2020 Allen D. Leman Swine Conference. Sain Paul, Minnesota, USA. 2020: 30 https://sites.google.com/a/umn.edu/leman-swine-conference/current-yearsconference\#h.xr8bmpwikouh. Accessed 10 Oct, 2020.

7. Gladue D. Development of live-attenuated vaccines for African swine fever virus. Allen D. Leman Swine Conference. Sain Paul, Minnesota, USA. 2020: 10. https://sites.google.com/a/umn.edu/leman-swine-conference/current-yearsconference\#h.xr8bmpwikouh. Accessed 10 Oct, 2020.

8. Yan Z. Controlling and eliminating African Swine Fever Virus from swine herd by qPCRbased test-removal through organized sampling. Allen D. Leman Swine Conference. Sain Paul, Minnesota, USA. 2020: 39. https://sites.google.com/a/umn.edu/leman-swineconference/current-years-conference\#h.xr8bmpwikouh. Accessed 10 Oct, 2020.

9. González L. Crisis sanitaria dispara envíos de carne de cerdo mexicana a China. El economista. https://www.eleconomista.com.mx/empresas/Crisis-sanitaria-disparaenvios-de-carne-de-cerdo-mexicana-a-China-20200227-0027.html. Consultado 10 Oct, 2020. 
10. FAO. Food and agriculture organization. La agricultura mundial en la perspectiva del año 2050.

http://www.fao.org/fileadmin/templates/wsfs/docs/Issues_papers/Issues_papers_SP/La _agricultura_mundial.pdf. Consultado 10 Oct, 2020.

11. Loosli CG. Synergism between respiratory viruses and bacteria. Yale J Biol Med 1968;40(5):522-540.

12. Saade G, Deblanc C, Bougon J, Bougon J, Marois-Créhan C, Fablet C, et al. Coinfections and their molecular consequences in the porcine respiratory tract. Vet Res 2020;(51):80.

13. Opriessnig T, Giménez-Lirola LG, Halbur PG. Polymicrobial respiratory disease in pigs. Anim Health Res Rev 2011;12(2):133-148.

14. Gottschalk M, Broes A. Actinobacillosis. In: Zimmerman JJ, et al, editors. $11^{\text {th }}$ ed. Diseases of swine. Hoboken, NJ, USA: Wiley-Blackwell; 2019:749-766.

15. Pieters MG, Maes D. Mycoplasmosis. In: Zimmerman JJ, Karriker LA, Ramirez A, Schwartz KJ, Stevenson GW, Zhang J. 11th ed. Diseases of swine. Hoboken, NJ, USA: Wiley-Blackwell; 2019:863-883.

16. Li B, Du L, Xu X, Sun B, Yu Z, Feng Z. et al. Transcription analysis on response of porcine alveolar macrophages to co-infection of the highly pathogenic porcine reproductive and respiratory syndrome virus and Mycoplasma hyopneumoniae. Virus Res 2015;22 (196):60-69.

17. Deblanc C, Gorin S, Quéguiner S, Gautier-Bouchardon AV, Ferré S, Amenna N, et al. Pre-infection of pigs with Mycoplasma hyopneumoniae modifies outcomes of infection with European swine influenza virus of H1N1, but not H1N2, subtype. Vet Microbiol 2012;157(1-2):96-105.

18. Gebhardt JT, Tokach MD, Dritz SS, DeRouchey JM, Woodworth JC, Goodband RD, et al. Postweaning mortality in commercial swine production II: review of infectious contributing factors. Transl Anim Sci 2020;4(2):485-506.

19. Silva GS, Yeske P, Morrison RB, Linhares DCL. Benefit-cost analysis to estimate the payback time and the economic value of two Mycoplasma hyopneumoniae elimination methods in breeding herds. Prev Vet Med 2019;(168):95-102.

20. Gottschalk M, Segura M. Streptococcosis. In: Zimmerman JJ, Karriker LA, Ramirez A, Schwartz KJ, Stevenson GW, Zhang J. 11th ed. Diseases of swine. Hoboken, NJ, USA: Wiley-Blackwell; 2019:934-950. 
21. Goyette-Desjardins G, Auger JP, Xu J, Segura M, Gottschalk M. Streptococcus suis, an important pig pathogen and emerging zoonotic agent-an update on the worldwide distribution based on serotyping and sequence typing. Emerg Microbes Infect 2014;3(6):e45.

22. Gottschalk M, Higgins R, Boudreau M. Use of polyvalent coagglutination reagents for serotyping of Streptococcus suis. J Clin Microbiol 1993;31(8):2192-2194.

23. Chatellier S, Harel J, Zhang Y, Gottschalk M, Higgins R, Devriese LA, et al. Phylogenetic diversity of Streptococcus suis strains of various serotypes as revealed by 16S rRNA gene sequence comparison. Int J Syst Bacteriol 1998;48(Pt 2):581-589.

24. Diosdado VF, Cordova LD, Socci EG, Morilla GA. Association between aujeszkys disease virus and/or Mycoplasma hyopneumoniae to increase Actinobacillus pleuropneumoniae infection. Reunión Nacional de Investigación Pecuaria en México. Veracruz, Ver. 1997:374.

25. Serrano-Rubio LE, Tenorio-Gutiérrez V, Suárez-Güemes F, Reyes-Cortés R, RodríguezMendiola M, Arias-Castro C. et al. Identification of Actinobacillus pleuropneumoniae biovars 1 and 2 in pigs using a PCR assay. Mol Cell Probes 2008;22(5-6):305-312.

26. Socci EG, Carrera SE, Diosdado VF. Polymerase Chain Reaction (PCR) for detection of Mycoplasma hyopneumoniae, responsable of Enzootic Pneumonia in pigs. J Anim Vet Adv 2011;10(23):3065-3068.

27. Alvarez-Ordóñez A, Martínez-Lobo FJ, Arguello H, Carvajal A, Rubio P. Swine dysentery: Aetiology, pathogenicity, determinants of transmission and the fight against the disease. Int J Environ Res Public Health 2013;10(5):1927-47.

28. Hampson D, Burrough E. Swine Dysentery and Brachyspiral Colitis. In: Zimmerman JJ, Karriker LA, Ramirez A, Schwartz KJ, Stevenson GW, Zhang J. $11^{\text {th }}$ ed. Diseases of swine. Hoboken, NJ, USA: Wiley-Blackwell; 2019:951-970.

29. Leite FL, Abrahante JE, Vasquez E, Vannucci F, Gebhart CJ, Winkelman N. et al. A cell proliferation and inflammatory signature is induced by Lawsonia intracellularis infection in swine. mBio 2019;10(1):e01605-18.

30. Denisova L. The problem of proliferative enteropathy is successfully solved. Svinovodstvo 2017;(4):67-68.

31. Vannucci F, Gebhart C, McOrist S. Proliferative Enteropathy. In: Zimmerman JJ, Karriker LA, Ramirez A, Schwartz KJ, Stevenson GW, Zhang J. $11^{\text {th }}$ ed. Diseases of swine. Hoboken, NJ, USA: Wiley-Blackwell; 2019:898-911. 
32. Griffith R, Carlson S, Krull A. Salmonellosis. In: Zimmerman JJ, Karriker LA, Ramirez A, Schwartz KJ, Stevenson GW, Zhang J. $11^{\text {th }}$ ed. Diseases of swine. Hoboken, NJ, USA: Wiley-Blackwell; 2019:912-925.

33. Martínez-Avilés M, Garrido-Estepa M, Álvarez J, de la Torre A. Salmonella surveillance systems in swine and humans in Spain: A Review. Vet Sci 2019;6(1):20.

34. Fairbrother J, Nadeau E. Colibacillosis. In: Zimmerman JJ, Karriker LA, Ramirez A, Schwartz KJ, Stevenson GW, Zhang J. 11th ed. Diseases of swine. Hoboken, NJ, USA: Wiley-Blackwell; 2019:807-834.

35. Cheng D, Zhu S, Su Z, Zuo W, Lu H. Prevalence and isoforms of the pathogenicity island ETT2 among Escherichia coli isolates from colibacillosis in pigs and mastitis in cows. Curr Microbiol 2012;(64):43-49.

36. Nordeste R, Tessema A, Sharma S, Kovac Z, Wang C, Morales R, et al. Molecules produced by probiotics prevent enteric colibacillosis in pigs. BMC Vet Res 2017;(13):335.

37. García CL, Socci EG, Barrón FL, Arriaga DC, Morilla GA. Diagnóstico de ileítis porcina por medio de la reacción en cadena de la polimerasa. Vet Méx 1998;29(3):263-267.

38. Socci EG, Diosdado VF, Carrera SE, Arriaga DC. Determinación de la frecuencia de piaras infectadas con Lawsonia intracellularis en México mediante la técnica de PCR. Téc Pecu Méx 2005;43(2):211-218.

39. Ontiveros CMDL, Mancera MA, Vázquez NJ, Tenorio GVR. Determinación de la existencia de plásmidos en aislamientos de Salmonella enteritidis (fagotipos 4 y 8 ) y su análisis en la resistencia antimicrobiana. Téc Pecu Méx 2004;42(3):325-332.

40. Vélez IA, Espinosa GJA, Cuevas RV, Diosdado VF, Buendía RG. Impacto de tecnologías pecuarias en el ingreso neto de porcicultores en México. Reunión Nacional de Investigación Pecuaria, Nuevo Vallarta, Nayarit. 2018:594-595.

41. Opriessnig T, Karuppannan AK, Castro AMMG, Xiao CT. Porcine circoviruses: current status, knowledge gaps and challenges. Virus Res 2020;(286):198044.

42. Ouyang T, Niu G, Liu X, Zhang X, Zhang Y, Ren L. Recent progress on porcine circovirus type 3. Infect Genet Evol 2019;(73):227-233.

43. Tischer I, Rasch R, Tochtermann G. Characterization of papovavirus-and picornaviruslike particles in permanent pig kidney cell lines. Zentralbl Bakteriol Orig A 1974;226(2):153-67. 
44. Tischer I, Gelderblom H, Vettermann W, Koch MA. A very small porcine virus with circular single-stranded DNA. Nature 1982;295(5844):64-6.

45. Harding JCS, Clark EG. Recognizing and diagnosing postweaning multisystemic wasting syndrome (PMWS) Swine Health Prod 1997;(5):201-203.

46. Harding JCS, Clark EG, Strokappe JH, Wilson PI, Ellis JA. Postweaning multisystemic wasting syndrome: Epidemiology and clinical presentation. Swine Health Prod 1998;(6):249-254.

47. Allan GM, Ellis JA. Porcine circoviruses: A review. J Vet Diagn Invest 2000;(12):3-14.

48. Ramírez-Mendoza H, Martínez C, Mercado C, Castillo-Juárez H, Hernández J, Segalés J. Porcine circovirus type 2 antibody detection in backyard pigs from Mexico City. Res Vet Sci 2007;(83):130-132.

49. Ramírez-Mendoza H, Castillo-Juárez H, Hernández J, Correa P, Segalés J. Retrospective serological survey of Porcine circovirus-2 infection in Mexico. Can J Vet Res 2009;(73):21-24.

50. Bedolla LF, Trujillo OME, Mendoza ES, Quintero RV, Alonso MR, Ramírez-Mendoza H. et al. Identification and genotyping of porcine circovirus type II (PCV2) in Mexico. VirusDisease 2018;(29):385-389.

51. De la Luz AJ, Rivera BJF, Gómez NL. Phylogenetic analysis of porcine circovirus type 3 infect a swine production system in Mexico City. Proc. 10th European Symposium of porcine health management. Barcelona, Spain. 2018:480.

52. DiosdadoVF, Socci EG, Martinez LA, Carrera SE, Santiago CJ. Study of porcine circovirus type 2 (PCV2) and porcine reproductive and respiratory syndrome virus (PRRSV) frequencies and coinfection in Mexican farrow to finish pig farms. J Vet Med Anim Health 2018;10(3):96-100.

53. Palinski R, Piñeyro P, Shang P, Yuan F, Guo R, Fang Y. et al. A novel porcine circovirus distantly related to known circoviruses is associated with porcine dermatitis and nephropathy syndrome and reproductive failure. J Virol 2016;91(1):e01879-16.

54. Hayashi S, Ohshima Y, Furuya Y, Nagao A, Oroku K, Tsutsumi N. et al. First detection of porcine circovirus type 3 in Japan. J Vet Med Sci 2018;80(9):1468-1472.

55. $\mathrm{Ku} \mathrm{X}$, Chen $\mathrm{F}$, Li $\mathrm{P}$, Wang $\mathrm{Y}, \mathrm{Yu} \mathrm{X}$, Fan $\mathrm{S}$, et al. Identification and genetic characterization of porcine circovirus type 3 in China. Transbound Emerg Dis 2017;64(3):703-708. 
56. Zhao D, Wang X, Gao Q, Huan C, Wang W, Gao S, et al. Retrospective survey and phylogenetic analysis of porcine circovirus type 3 in Jiangsu province, China, 2008 to 2017. Arch Virol 2018;163(9):2531-2538.

57. Collins PJ, McKillen J, Allan G. Porcine circovirus type 3 in the UK. Vet Rec 2017;181(22):599.

58. Faccini S, Barbieri I, Gilioli A, Sala G, Gibelli LR, Moreno A. et al. Detection and genetic characterization of Porcine circovirus type 3 in Italy. Transbound Emerg Dis 2017;64(6):1661-1664.

59. Fux R, Söckler C, Link EK, Renken C, Krejci R, Sutter G, et al. Full genome characterization of porcine circovirus type 3 isolates reveals the existence of two distinct groups of virus strains. Virol J 2018;15(1):25.

60. Ye X, Berg M, Fossum C, Wallgren P, Blomström AL. Detection and genetic characterisation of porcine circovirus 3 from pigs in Sweden. Virus Genes 2018;54(3):466-469.

61. Tochetto C, Lima DA, Varela APM, Loiko MR, Paim WP, Scheffer CM, et al. Fullgenome sequence of porcine Circovirus type 3 recovered from serum of sows with stillbirths in Brazil. Transbound Emerg Dis 2018;65(1):5-9.

62. Zimmerman JJ, Dee SA, Holtkamp DJ, Murtaugh MP, Stadejek T, Stevenson GW, et al. Porcine Reproductive and Respiratory Syndrome Viruses (Porcine Arteriviruses). In: Zimmerman JJ, Karriker LA, Ramirez A, Schwartz KJ, Stevenson GW, Zhang J. $11^{\text {th }}$ ed. Diseases of swine. Hoboken, NJ, USA: Wiley-Blackwell; 2019:685-708.

63. Hill H. Overview and history of mystery swine disease (swine infertility/respiratory syndrome). Proceedings of the mystery swine disease committee meeting. Madison, WI, USA. 1990:29-30.

64. Wensvoort G, Terpstra C, Pol JM, ter Laak EA, Bloemraad M, de Kluyver EP, et al. Mystery swine disease in The Netherlands: the isolation of Lelystad virus. Vet Q 1991;13(3):121-30.

65. Collins JE, Benfield DA, Christianson WT, Harris L, Hennings JC, Shaw DP, et al. Isolation of swine infertility and respiratory syndrome virus (isolate ATCC VR-2332) in North America and experimental reproduction of the disease in gnotobiotic pigs. $\mathbf{J}$ Vet Diagn Invest 1992;4(2):117-126. 
66. Meng XJ, Paul PS, Halbur PG, Lum MA. Phylogenetic analyses of the putative M (ORF 6) and $\mathrm{N}$ (ORF 7) genes of porcine reproductive and respiratory syndrome virus (PRRSV): implication for the existence of two genotypes of PRRSV in the U.S.A. and Europe. Arch Virol 1995;140(4):745-755.

67. Neumann EJ, Kliebenstein JB, Johnson CD, Mabry JW, Bush EJ, Seitzinger AH, et al. Assessment of the economic impact of porcine reproductive and respiratory syndrome on swine production in the United States. J Am Vet Med Assoc 2005;227(3):385-92.

68. Amador, C.J. Evaluación del impacto económico del virus PRRS en granjas porcinas en México [tesis maestría]. Ciudad de México, México. Universidad Nacional Autónoma de México; 2016.

69. Millán SF, Cantó AG, Weimersheimer RJ, Coba AMA, Anaya EAM, Correa GP. Estudio seroepidemiológico para determinar la presencia de anticuerpos contra el virus del síndrome disgenésico del cerdo en México. Téc Pecu Méx 1994;32(3):139-144.

70. Diosdado VF, Socci EG, Morilla GA. Frecuencia de granjas infectadas con el virus del síndrome disgenésico y respiratorio del cerdo (PRRS) en México [resumen]. Reunión Anual de Investigación Pecuaria en México. Veracruz, México. 1997:375.

71. Sierra N, Ramirez R, Mota D. Isolation of PRRS virus in Mexico: a clinical, serological and virological study. Arch Med Vet 2000;32(1):1-9.

72. Toiber AE. Análisis de la variabilidad antigénica y genética del virus del síndrome respiratorio y reproductivo porcino (PRRSV) en cepas mexicanas [tesis maestría]. Ciudad de México, México. Universidad Nacional Autónoma de México; 2014.

73. Martínez-Bautista NR, Sciutto-Conde E, Cervantes-Torres J, Segura-Velázquez R, Mercado García MC, Ramírez-Mendoza H, et al. Phylogenetic analysis of ORF5 and ORF7 of porcine reproductive and respiratory syndrome (PRRS) virus and the frequency of wild-type PRRS virus in México. Transbound Emerg Dis 2018;65(4):993-1008.

74. Stephano HA, Gay GM, Ramírez TC. Encephalomyelitis, reproductive failure and corneal opacity (blue eye) in pigs, associated with a paramyxovirus infection. Vet Rec 1988;122(1):6-10. Erratum in: Vet Rec 1988;122(17):420.

75. Moreno-López J, Correa-Girón P, Martinez A, Ericsson A. Characterization of a paramyxovirus isolated from the brain of a piglet in Mexico. Arch Virol 1986;91(34):221-31.

76. Sundqvist A, Berg M, Hernandez-Jauregui P, Linné T, Moreno-López J. The structural proteins of a porcine paramyxovirus (LPMV). J Gen Virol 1990;71( Pt 3):609-613. 
77. Rima B, Balkema-Buschmann A, Dundon WG, Duprex P, Easton A, Fouchier R, et al. ICTV virus taxonomy profile: Paramyxoviridae. J Gen Virol 2019;100(12):1593-1594.

78. Cuevas-Romero JS, Blomström AL, Berg M. Molecular and epidemiological studies of Porcine rubulavirus infection - an overview. Infect Ecol Epidemiol 2015;(5):29602.

79. Ramirez-Mendoza H, Hernandez-Jauregui P, Reyes-Leyva J, Zenteno E, Moreno-Lopez J, Kennedy S. Lesions in the reproductive tract of boars experimentally infected with Porcine rubulavirus. J Comp Pathol 1997;117(3):237-52.

80. Hernández-Jáuregui P, Ramírez-Mendoza H, Mercado-García C, Moreno-López J, Kennedy S. Experimental Porcine rubulavirus (La Piedad-Michoacan virus) infection in pregnant gilts. J Comp Pathol 2004;130(1):1-6.

81. Rivera-Benitez JF, Cuevas-Romero S, Pérez-Torres A, Reyes-Leyva J, Hernández J, Ramírez-Mendoza H. Respiratory disease in growing pigs after Porcine rubulavirus experimental infection. Virus Res 2013a;176(1-2):137-43.

82. Rivera-Benitez JF, Martínez-Bautista R, Pérez-Torres A, García-Contreras ADC, ReyesLeyva J, Hernández $\mathrm{J}$, et al. Persistence of Porcine rubulavirus in experimentally infected boars. Vet Microbiol 2013b;162(2-4):491-98.

83. Herrera J, Gómez-Núñez L, Lara-Romero R, Diosdado F, Martínez-Lara A, Jasso M. et al. Acute neurologic disease in Porcine rubulavirus experimentally infected piglets. Virus Res 2017;230:50-58.

84. Ramírez MH, Carreón NR, Mercado GC, Rodríguez TJ. Hemoaglutinación e inhibición de la hemoaglutinación del paramixovirus porcino a través de la modificación de algunas variables que participan en la prueba. Vet Méx 1996;27(3):257-59.

85. Cuevas-Romero S, Blomström AL, Alvarado A, Hernández-Jauregui P, Rivera-Benitez F, Ramírez-Mendoza H, et al. Development of a real-time RT-PCR method for detection of Porcine rubulavirus (PoRV-LPMV). J Virol Methods 2013;189(1):1-6.

86. Rivera-Benitez JF, García-Contreras Adel C, Reyes-Leyva J, Hernández J, SánchezBetancourt JI, Ramírez-Mendoza H. Efficacy of quantitative RT-PCR for detection of the nucleoprotein gene from different Porcine rubulavirus strains. Arch Virol 2013c;158(9):1849-56.

87. Garcia-Barrera AA, Del Valle A, Montaño-Hirose JA, Barrón BL, Salinas-Trujano J, Torres-Flores J. Full-genome sequencing and phylogenetic analysis of four neurovirulent Mexican isolates of Porcine rubulavirus. Arch Virol 2017;162(6):17651768. 
88. Escobar-López AC, Rivera-Benitez JF, Castillo-Juárez H, Ramírez-Mendoza H, TrujilloOrtega ME, Sánchez-Betancourt JI. Identification of antigenic variants of the Porcine rubulavirus in sera of field swine and their seroprevalence. Transbound Emerg Dis 2012;59(5):416-20.

89. Rivera-Benitez JF, Rosas-Estrada K, Pulido-Camarillo E, de la Peña-Moctezuma A, Castillo-Juárez H, Ramírez-Mendoza H. Serological survey of veterinarians to assess the zoonotic potential of three emerging swine diseases in Mexico. Zoonoses Public Health 2014;61(2):131-137.

90. Thibault PA, Watkinson RE, Moreira-Soto A, Drexler JF, Lee B. Zoonotic potential of emerging paramyxoviruses: knowns and unknowns. Adv Virus Res 2017;(98):1-55.

91. Cuevas-Romero JS, Rivera-Benítez JF, Hernández-Baumgarten E, Hernández-Jaúregui P, Vega M, Blomström AL, et al. Cloning, expression and characterization of potential immunogenic recombinant hemagglutinin-neuraminidase protein of Porcine rubulavirus. Protein Expr Purif 2016;(128):1-7.

92. Cerriteño-Sánchez JL, Santos-López G, Rosas-Murrieta NH, Reyes-Leyva J, CuevasRomero S, Herrera-Camacho I. Production of an enzymatically active and immunogenic form of ectodomain of Porcine rubulavirus hemagglutinin-neuraminidase in the yeast Pichia pastoris. J Biotechnol 2016;(223):52-61.

93. Siañez-Estrada LI, Rivera-Benítez JF, Rosas-Murrieta NH, Reyes-Leyva J, Santos-López G, Herrera-Camacho I. Immunoinformatics approach for predicting epitopes in $\mathrm{HN}$ and F proteins of Porcine rubulavirus. PLoS One. 2020;15(9):e0239785.

94. MacLachlan J, Dubovi E. Fenner's Veterinary Virology. $5^{\mathrm{a}}$ ed. London, UK: Academic Press; 2016.

95. Jung K, Saif LJ. Porcine epidemic diarrhea virus infection: Etiology, epidemiology, pathogenesis and immunoprophylaxis. Vet J 2015;204(2):134-43.

96. Chen Q, Gauger P, Stafne M, Thomas J, Arruda P, Burrough E, et al. Pathogenicity and pathogenesis of a United States porcine deltacoronavirus cell culture isolate in 5-dayold neonatal piglets. Virology 2015;482:51-59.

97. Boniotti MB, Papetti A, Lavazza A, Alborali G, Sozzi E, Chiapponi C, et al. Porcine epidemic diarrhea virus and discovery of a recombinant swine enteric coronavirus. Italy Emerg Infect Dis 2016;22(1):83-87.

98. Saif, L, Wang, Q, Vlasova, A, Jung, K, Xiao, S. Coronaviruses. In: Zimmerman JJ, Karriker LA, Ramirez A, Schwartz KJ, Stevenson GW, Zhang J. $11^{\text {th }}$ ed. Diseases of swine. Hoboken, NJ, USA: Wiley-Blackwell; 2019:488-523. 
99. Huang Y, Dickerman A, Pineyro P, Li L, Fang L, Kiehne R, et al. Origin, evolution, and genotyping of emergent porcine epidemic diarrhea virus strains in the United States. mBio 2013;4(5):e00737-00713.

100. Fajardo R, Alpizar A, Martinez A, Quintero, V, Diosdado, F, Córdova, D, et al. Two cases report of PED in different states in México. International Pig Veterinary Society (IPVS) Congress Cancun, Mexico. 2014:645.

101. Rivera-Benítez JF, Gómez-Núñez L, Diosdado VF, Socci EG, De la Luz AJ, Quintero $\mathrm{V}$, et al. Detección de nuevos coronavirus causantes de diarreas agudas en cerdos lactantes. Reunión Nacional de Investigación Pecuaria. Estado de México, México. 2015:166-167.

102. OIE-WAHID. Follow-up report No.1 Final Report. Virus de la diarrea epidémica porcina, México. 2016. https://www.oie.int/wahis_2/public/wahid.php/Reviewreport/Review?reportid=19584 Accessed 17 Oct, 2020.

103. PORCIMEX. Compendio estadístico del sector porcícola. 2015. México. http://www.porcimex.org/Compendio\%20Estadistico\%202015.pdf Consultado 17 Oct, 2020.

104. Trujillo-Ortega M, Beltrán-Figueroa R, García-Hernández M, Juárez-Ramírez M, Sotomayor-González A, Hernández-Villegas E, et al. Isolation and characterization of porcine epidemic diarrhea virus associated with the 2014 disease outbreak in Mexico: case report. BMC Vet Res 2016;(12):132.

105. DOF. Diario Oficial de la Federación. Acuerdo mediante el cual se dan a conocer en los Estados Unidos Mexicanos las enfermedades y plagas exóticas y endémicas de notificación obligatoria de los animales terrestres y acuáticos. 2018. https://dof.gob.mx/nota_detalle.php?codigo=5545304\&fecha=29/11/2018. Consultado 17 Oct, 2020.

106. Lara-Romero R, Gómez-Núñez L, Cerriteño-Sánchez JL, Márquez-Valdelamar L, Mendoza-Elvira S, Ramírez-Mendoza H, et al. Molecular characterization of the spike gene of the porcine epidemic diarrhea virus in Mexico, 2013-2016. Virus genes 2018;54(2): 215-224.

107. Barrera AM. Construcción de un sistema de expresión para la proteína $\mathrm{N}$ del virus de la diarrea epidémica porcina (vDEP) en E. coli y caracterización antigénica en ensayos inmunoabsorbentes [tesis maestría]. Ciudad de México, México. Universidad Nacional Autónoma de México; 2018. 
108. Castillo CK. Estudio comparativo de la virulencia de una cepa epidémica y una cepa INDEL del virus de diarrea epidémica porcina [tesis maestría]. Ciudad de México, México. Universidad Nacional Autónoma de México; 2019.

109. Zapata MM. Evaluación de un biológico recombinante del virus de diarrea epidémica porcina en cerdos en engorda [tesis licenciatura]. Ciudad de México, México. Universidad Nacional Autónoma de México; 2020.

110. Arenas LT. Escalamiento a biorreactor de la producción heteróloga y la purificación de dos fragmentos de la proteína $\mathrm{S}$ del vDEP en Escherichia coli [tesis maestría]. Instituto Nacional de México. Instituto Tecnológico de Celaya; 2018.

111. Ma W, Lager KM, Vincent AL, Janke BH, Gramer MR, Richt JA. The role of swine in the generation of novel influenza viruses. Zoonoses Public Health 2009;56(6-7):326-37.

112. Yoon SW, Webby RJ, Webster RG. Evolution and ecology of influenza A viruses. Curr Top Microbiol Immunol 2014;(385):359-375.

113. Ma W, García-Sastre A, Schwemmle M. Expected and unexpected features of the newly discovered bat influenza A-like viruses. PLoS Pathog 2015;11(6):e1004819.

114. Ma W. Swine influenza virus: Current status and challenge. Virus Res 2020;(288):198118.

115. Krammer F, Smith GJD, Fouchier RAM, Peiris M, Kedzierska K, Doherty PC, et al. Influenza. Nat Rev Dis Primers 2018;4(1):3.

116. Medina RA, García-Sastre A. Influenza A viruses: new research developments. Nat Rev Microbiol 2011;9(8):590-603.

117. Denney L, Ho LP. The role of respiratory epithelium in host defense against influenza virus infection. Biomed J 2018;41(4):218-233.

118. Taubenberger JK, Kash JC. Influenza virus evolution, host adaptation, and pandemic formation. Cell Host Microbe 2010;7(6):440-51.

119. Torremorell M, Allerson M, Corzo C, Diaz A, Gramer M. Transmission of influenza A virus in pigs. Transbound Emerg Dis 2012;59 (Suppl 1):68-84.

120. Saavedra-Montañez M, Vaca L, Ramírez-Mendoza H, Gaitán-Peredo C, BautistaMartínez R, Segura-Velázquez R. et al. Identification and genomic characterization of influenza viruses with different origin in Mexican pigs. Transbound Emerg Dis 2019;66 (1):186-194. 
121. Janke BH. Clinicopathological features of Swine influenza. Curr Top Microbiol Immunol 2013;(370):69-83.

122. Janke BH. Influenza A virus infections in swine: pathogenesis and diagnosis. Vet Pathol 2014;51(2):410-426.

123. Saavedra-Montañez M, Castillo-Juárez H, Sánchez-Betancourt I, Rivera-Benitez JF, Ramírez-Mendoza H. Serological study of influenza viruses in veterinarians working with swine in Mexico. Arch Virol 2017;162(6):1633-1640.

124. Mena I, Nelson MI, Quezada-Monroy F, Dutta J, Cortes-Fernández R, Lara-Puente JH, et al. Origins of the $2009 \mathrm{H} 1 \mathrm{~N} 1$ influenza pandemic in swine in Mexico. Elife 2016;5:e16777.

125. Juárez-Ramírez M, Sánchez-Betancourt I, Trujillo-Ortega ME, Mendoza-Elvira S, Carreón-Nápoles R, Fuente-Martínez B, et al. Clinical evaluation, serological response and lesions generated by the A/Mexico/La Gloria-3/2009/H1N1 and A/swine/New Jersey/11/1976/H1N1 influenza viruses in colostrated and non-colostrated pigs. Virusdisease 2019;30(3):433-440.

126. Saavedra-Montañez M, Carrera-Aguirre V, Castillo-Juárez H, Rivera-Benitez F, RosasEstrada K, Pulido-Camarillo E. et al. Retrospective serological survey of influenza viruses in backyard pigs from Mexico City. Influenza Other Respir Viruses 2013;7(5):827-32.

127. Van Reeth K, Ma W. Swine influenza virus vaccines: to change or not to change-that's the question. Curr Top Microbiol Immunol 2013;(370):173-200.

128. Diosdado VF, González-Vega D, Moles-Cervantes LP y Morilla GM. Association between antibodies against porcine reproductive and respiratory syndrome virus and other pathogens. Vet Méx 2004;35(2):147-152.

129. Rivera-Benitez JF, De la Luz-Armendáriz J, Saavedra-Montañez M, Jasso-Escutia MÁ, Sánchez-Betancourt I, Pérez-Torres A, et al. Co-infection of classic swine H1N1 influenza virus in pigs persistently infected with Porcine rubulavirus. Vet Microbiol 2016;(184):31-39.

130. Mengeling WL, Lager KM, Vorwald AC. The effect of porcine parvovirus and porcine reproductive and respiratory syndrome virus on porcine reproductive performance. Anim Reprod Sci 2000;(60-61):199-210.

131. Truyen U, Streck AF. Parvoviruses. In: Zimmerman JJ, Karriker LA, Ramirez A, Schwartz KJ, Stevenson GW, Zhang J. $11^{\text {th }}$ ed. Diseases of swine. Hoboken, NJ, USA: Wiley-Blackwell; 2019:611-621. 
132. Xiao CT, Giménez-Lirola LG, Jiang YH, Halbur PG, Opriessnig T. Characterization of a novel porcine parvovirus tentatively designated PPV5. PLoS One 2013;8(6):e65312.

133. Streck AF, Bonatto SL, Homeier T, Souza CK, Gonçalves KR, Gava D, et al. High rate of viral evolution in the capsid protein of porcine parvovirus. J Gen Virol 2011;92(Pt 11):2628-2636.

134. Cadar D, Dán Á, Tombácz K, Lőrincz M, Kiss T, Becskei Z, et al. Phylogeny and evolutionary genetics of porcine parvovirus in wild boars. Infect Genet Evol 2012;12(6):1163-71.

135. Shangjin C, Cortey M, Segalés J. Phylogeny and evolution of the NS1 and VP1/VP2 gene sequences from porcine parvovirus. Virus Res 2009;140(1-2):209-215.

136. Streck AF, Homeier T, Foerster T, Fischer S, Truyen U. Analysis of porcine parvoviruses in tonsils and hearts from healthy pigs reveals high prevalence and genetic diversity in Germany. Arch Virol 2013a;(158):1173-1780.

137. Zeeuw EJL, Leinecker N, Herwig V, Selbitz HJ, Truyen U. Study of the virulence and cross-neutralization capability of recent porcine parvovirus field isolates and vaccine viruses in experimentally infected pregnant gilts. J Gen Virol 2007;88(Pt 2):420-427.

138. Ramírez MH, Sánchez MPH, Zepeda MOO, Espino RMG, Correa GP. Seroprevalencia de anticuerpos contra parvovirus porcino (PVP) en cerdas y ratas en granjas porcinas del ciclo completo. Téc Pecu Méx 1991;29(3):159-164.

139. Socci EG, Diosdado VF, González VG, Corona BE, Morilla GA. Perfil serológico de granjas donde se vacunaba o no a las hembras contra el parvovirus porcino. Téc Pecu Méx 1996;34(2):104-110.

140. Carrera-Aguirre VM, Mercado GC, Carreón NR, Haro TM. Seroprevalencia y frecuencia de títulos de anticuerpos contra parvovirus porcino en cerdos de traspatio del Distrito Federal en el periodo 2000-2009. Congreso Nacional AMVEC. Puerto Vallarta, Jalisco, México. 2011:1

141. Zhou B. Classical Swine Fever in China-An update minireview. Front Vet Sci 2019;(6):187.

142. Martínez MA, Torres CJ, Martínez SA, Bordier LD, Partida OY, Morilla GA. Análisis de la cadena de frío de la vacuna contra la fiebre porcina clásica. Téc Pecu Méx 1992;30(1):23-30.

143. Coba AMA, Baez RU, Anaya EA, Correa GP. Protección conferida por la vacuna PAV250 contra la fiebre porcina clásica al vacunar cerdos de uno, siete, 15 y 21 días de edad. Téc Pecu Méx 1992;30(2):91-99. 
144. Báez RU, Coba AMA, Anaya EA, Correa GP, Rosales OC. Inocuidad del virus vacunal PAV-250 contra la fiebre porcina clásica (FPC) en cerdas en celo y gestantes, sin antecedentes de vacunación. Téc Pecu Méx 1995;33(3):135-147.

145. Martínez SA, Cisneros MI, González VD, Arriaga DC, Morilla GA. Perfil inmunológico de cerdos inoculados con el virus de la fiebre porcina clásica. Téc Pecu Méx 1993;31(3):128-136.

146. Aguirre BF, Aguilar OP, Martínez SA, Morilla GA. Aspectos epidemiológicos de la campaña de vacunación intensiva contra la fiebre porcina clásica en el estado de Guanajuato. 1991-1993. Téc Pecu Méx 1994;32(2):98-104.

147. Socci EG, Diosdado VF, Carrera SE, Macías GM, Arriaga DC, Morilla GA. Establecimiento de la técnica de RT-PCR para el diagnóstico de la fiebre porcina clásica en México. Téc Pecu Méx 2003;41(1):105-110.

148. Socci EG, Diosdado VF, Carrera SE, Macías GM, Arriaga DC, Morilla GA. Comparison between vaccinal and field CSF virus strains in Mexico. International Pig Veterinary Society (IPVS) Congress Ames, Iowa, USA. 2002:u 182.

149. Zuckermann FA. Aujeszky's disease virus: opportunities and challenges. Vet Res 2000;31(1):121-131.

150. Bachtold, M. Una nueva enfermedad en México, el mal de Aujeszky. Rev Tierra 1945; 1001:42-43.

151. Martell DM, Alcocer BR, Cerón MF, Lozano SJ, Del Valle PP, Auró AA. Aislamiento y caracterización del virus de la Enfermedad de Aujeszky o Pseudorrabia en México. Téc Pecu Méx 1971;(18):27-41.

152. Morilla GA, Diosdado VF, Corona BE, Soria PS, González VD. Perfiles serológicos de granjas porcinas infectadas con el virus de la enfermedad de Aujeszky. Téc Pecu Méx 1995;33(2):92-99.

153. Diosdado VF, Corona BE, González VD, Socci EG, Morilla GA. Perfil serológico de piaras donde se vacunaba a las cerdas contra el virus de la enfermedad de Aujeszky. Téc Pecu Méx 1995;33(2):116-120.

154. Diosdado VF, Córdova LD, Socci EG, González VD, Morilla GA. Sinergismo potencial entre el virus de la enfermedad de Aujeszky, Mycoplasma hyopneumoniae y Actinobacillus pleuropneumoniae en cerdos de engorda. Téc Pecu Méx 1999a;37(1):2330. 
155. Diosdado VF, Castro GD, Rosales OC, Calderón CA, Campomanes CA, Morilla GA. Inmunogenicidad de seis vacunas de virus inactivado contra la enfermedad de Aujeszky. Téc Pecu Méx 1999b;37(1):59-62.

156. Cuevas SC, Guzmán HM, De Paz VO, Colmenares VG, Hernández BE, Pérez GE. Desarrollo y evaluación de un Dot-ELISA como prueba tamiz para el diagnóstico de la enfermedad de Aujeszky en México. Téc Pecu Méx 1997;35(3):170-176.

157. Coba AMA, Socci EG, Zapata SL, Carrera SE, Chávez CE. Polymerase Chain Reaction for Aujeszky disease in Mexico. J Anim Vet Adv 2012;11(22):4217-4220.

158. Gaudreault NN, Madden DW, Wilson WC, Trujillo JD, Richt JA. African Swine Fever Virus: An emerging DNA arbovirus. Front Vet Sci 2020;(7):215.

159. Dixon LK, Sun H, Roberts H. African swine fever. Antiviral Res 2019;165:34-41.

160. Malogolovkin A, Kolbasov D. Genetic and antigenic diversity of African swine fever virus. Virus Res 2019;271:197673.

161. Blome S, Gabriel C, Beer M. Pathogenesis of African swine fever in domestic pigs and European wild boar. Virus Res 2013;173(1):122-130.

162. Boinas FS, Wilson AJ, Hutchings GH, Martins C, Dixon LJ. The persistence of African swine fever virus in field-infected Ornithodoros erraticus during the ASF endemic period in Portugal. PLoS One 2011;6(5):e20383.

163. Laddomada A, Rolesu S, Loi F, Cappai S, Oggiano A, Madrau MP, et al. Surveillance and control of African Swine Fever in free-ranging pigs in Sardinia. Transbound Emerg Dis 2019;66(3):1114-1119.

164. Cwynar P, Stojkov J, Wlazlak K. African Swine Fever status in Europe. Viruses 2019;11(4):310.

165. Gabriel C, Blome S, Malogolovkin A, Parilov S, Kolbasov D, Teifke JP. et al. Characterization of African swine fever virus Caucasus isolate in European wild boars. Emerg Infect Dis 2011;17(12):2342-2345.

166. O'Donnell V, Risatti GR, Holinka LG, Krug PW, Carlson J, Velazquez-Salinas L. et al. Simultaneous deletion of the $9 \mathrm{gl}$ and UK genes from the African swine fever virus Georgia 2007 isolate offers increased safety and protection against homologous challenge. J Virol 2016;91(1):e01760-16. 
167. Borca MV, Ramirez-Medina E, Silva E, Vuono E, Rai A, Pruitt S. et al. Development of a highly effective African swine fever virus vaccine by deletion of the i1771 gene results in sterile immunity against the current epidemic Eurasia strain. J Virol 2020a;94(7):e02017-19.

168. Ramirez-Medina E, Vuono E, Pruitt S, Rai A, Silva E, Zhu J. et al. X69R is a nonessential gene that, when deleted from African swine fever, does not affect virulence in swine. Viruses 2020a;12(9):918.

169. Gaudreault NN, Richt JA. Subunit vaccine approaches for African Swine Fever Virus. Vaccines (Basel) 2019;7(2):56.

170. Bosch-Camós L, López E, Rodriguez F. African swine fever vaccines: a promising work still in progress. Porcine Health Manag 2020;(6):17.

171. O'Donnell V, Holinka LG, Gladue DP, Sanford B, Krug PW, Lu X, et al. African swine fever virus Georgia isolate harboring deletions of mgf360 and mgf505 genes is attenuated in swine and confers protection against challenge with virulent parental virus. J Virol 2015;89(11):6048-6056.

172. Borca MV, O'Donnell V, Holinka LG, Risatti GR, Ramirez-Medina E, Vuono EA, et $a l$. Deletion of CD2-like gene from the genome of African swine fever virus strain Georgia does not attenuate virulence in swine. Sci Rep 2020b;10(1):494.

173. Ramirez-Medina E, Vuono EA, Rai A, Pruitt S, Silva E, Velazquez-Salinas L, et al. The C962R ORF of African swine fever strain Georgia is non-essential and not required for virulence in swine. Viruses 2020b;12(6):676.

174. Ramirez-Medina E, Vuono E, Pruitt S, Rai A, Silva E, Zhu J, et al. X69R is a nonessential gene that, when deleted from African swine fever, does not affect virulence in swine. Viruses 2020c;12(9):918. 